\title{
Automatic image analysis for decision support in rheumatoid arthritis and osteoporosis
}

\author{
Johan Kälvesten
}

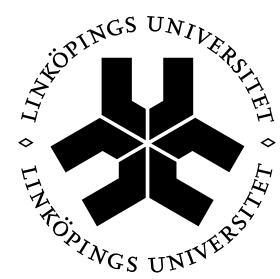

\section{Linköping University}

Department of Medical and Health Sciences, Division of Radiology Faculty of Health Sciences Linköpings universitet, SE-581 83 Linköping, Sweden Linköping 2015

\section{Center for Medical lmage sience and Visualization}

Center for Medical Image Science and Visualisation (CMIV)

Linköping University Hospital, SE-581 85 Linköping, Sweden 
Automatic image analysis for decision support in rheumatoid arthritis and osteoporosis

Linköping University Medical Dissertations, No. 1433

Copyright (C) 2015 Johan Kälvesten, unless otherwise noted

Department of Medical and Health Sciences

Linköpings universitet

SE-581 83 Linköping, Sweden

ISSN: 0345-0082

ISBN: 978-91-7519-170-6

Printed in Sweden by LiU-Tryck, Linköping, 2015 
Don't let perfect be the enemy of the possible 


\section{Abstract}

Low-energy trauma and fragility fractures represent a major public health problem. The societal cost of the fragility fractures that occurred in Sweden 2010 has been estimated at $€ 4$ billion.

In rheumatoid arthritis (RA), patient outcomes have improved greatly in recent years. However, the therapeutic decision making is still hampered by a lack of effective validated biomarkers. The cost of RA in Sweden 2010 has been estimated at $€ 600$ million, of which biologic drugs was $€ 180$ million.

Digital X-ray radiogrammetry (DXR) is a method to measure bone mineral density (BMD) in the metacarpals of the hand. It can be applied opportunistically in several workflows where a person is already at an X-ray machine, including fracture repositioning follow up, mammography screening and hand imaging in RA. This thesis explored DXR-BMD as a marker to identify individuals who would benefit from anti-osteoporotic treatment, change rate of DXR-BMD as a biomarker in RA and under what conditions historical X-ray images can be used to estimate DXR-BMD. An automated method for measurement of joint space width in metacarpophalangeal and interphalangeal joints was also developed and evaluated as a biomarker in RA.

Low DXR-BMD was predictive for hip fractures and predicted fragility fractures to a comparable degree as other BMD measurement sites. Rapid decrease of DXR-BMD was a strong and independent predictor for progression of radiographic damage in RA when manual radiographic progression scores were not available. Change of metacarpal joint space width was a statistically significant but weak predictor of joint space narrowing score progression. Guidelines and considerations for use of historical X-ray radiographs for DXR-BMD measurements in clinical trials have been developed and published. 


\section{Populärvetenskaplig sammanfattning}

Benskörhetsrelaterade frakturer är ett stort hälsoproblem och en stor samhällsekonomisk belastning i Sverige. Den ekonomiska kostnaden enbart för de benskörhetsrelaterade frakturer som inträffade i Sverige under 2010 har uppskattats till 14 miljarder kronor om man exkluderar de negativa hälsoeffekterna för de personer som drabbas och 39 miljarder kronor om man räknar med förlust av kvalitetsjusterade levnadsår.

Även reumatoid artrit (RA) är en sjukdom med stora hälsomässiga och ekonomiska konsekvenser. Stora framsteg i behandlingen av sjukdomen har gjorts under de senaste årtiondena och nydebuterade patienter idag har betydligt lägre risk för handikapp än för 20 år sedan. Trots framstegen så försvåras fortfarande det kliniska beslutsfattandet av begränsningar med de biomarkörer som finns tillgängliga vid klinikerna. Kostnaden för RA i Sverige 2010 har uppskattats till 5,6 miljarder kronor varav knappt en tredjedel utgjordes av biologiska läkemedel.

Automatiserad digital röntgenradiogrammetri (DXR) är en metod att mäta innehållet av benmineral i skelettet (BMD) i handen. Då metoden baseras på en enkel handröntgen kan man tänka sig flera vårdflöden där metoden kan appliceras opportunistiskt när en patient redan står vid en röntgenmaskin, till exempel vid uppföljning efter handledsfraktur, vid mammografi eller vid handröntgen inom reumatoid artrit.

I den här avhandlingen studerades DXR-BMD som en markör för att identifiera individer som skulle ha nytta av benstärkande behandling, förändring av bentätheten i handen som biomarkör för att stödja behandlingsbeslut inom RA samt under vilka förutsättningar man kan använda historiska röntgenbilder till att uppskatta bentätheten i handen. En metod för att med automatisk bildanalys mäta vidd av ledspalter i händerna utvecklades också och utvärderades som biomarkör inom RA.

Låg bentäthet $\mathrm{i}$ handen var starkt prediktivt för att senare drabbas av höftfraktur. En snabb sänkning av bentätheten i handen var en stark markör för utveckling av ledskador hos patienter med reumatoid artrit. Minskning av vidden av de ledspalter som utvärderades var en statistiskt signifikant men svag prediktor för utveckling av ledskada. Riktlinjer för hur man kan använda historiska handröntgenbilder för att uppskatta bentätheten har också tagits fram. 


\section{Contents}

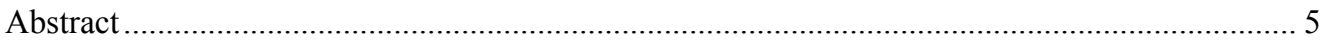

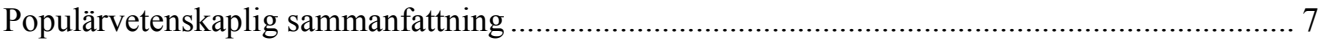

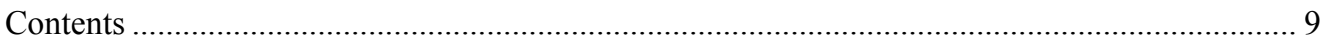

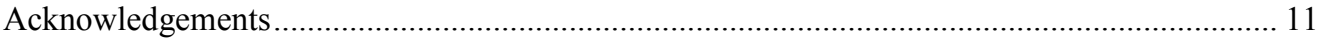

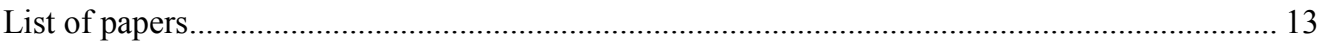

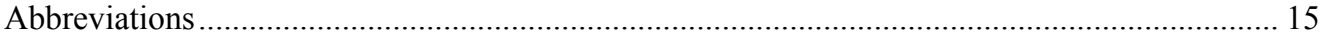

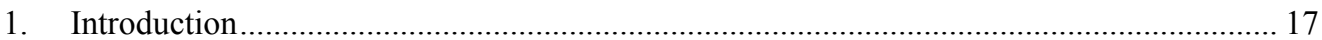

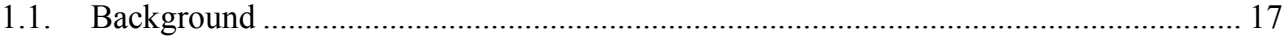

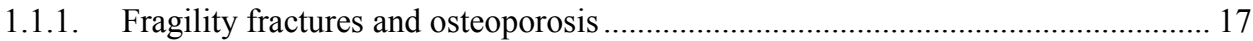

1.1.2. Rheumatoid arthritis, bone involvement and peri-articular osteoporosis ............... 18

1.1.3. Measurement of bone mineral density ........................................................... 19

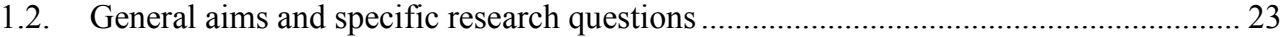

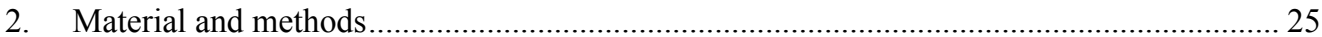

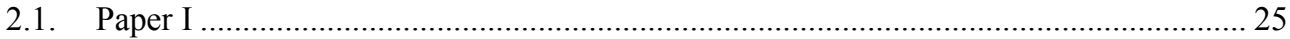

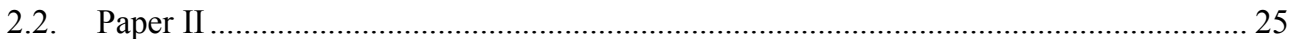

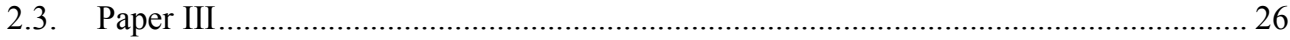

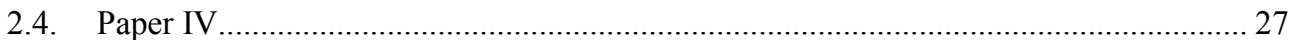

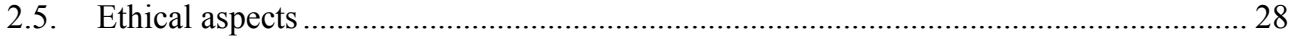

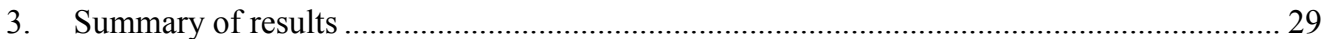

3.1. Paper I: Does digital X-ray radiogrammetry have a role in identifying patients at increased risk for joint destruction in early rheumatoid arthritis?

3.2. Paper II: Potential sources of quantification error when retrospectively assessing metacarpal bone loss from historical radiographs by using digital X-ray radiogrammetry: an experimental study

3.3. Paper III: Digital X-ray radiogrammetry of hand or wrist radiographs can predict hip fracture risk--a study in 5,420 women and 2,837 men.

3.4. Paper IV: Reliability, validity and feasibility of a novel fully automated quantitative method developed for measurement of digital joint space width in inflammatory arthritis..... 33 


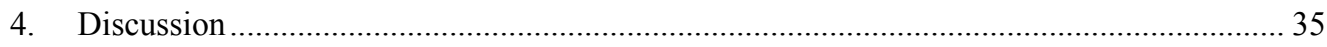

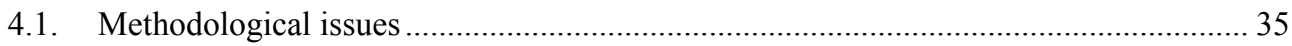

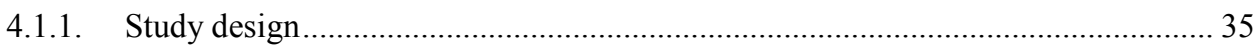

4.1.2. Representativeness of the study populations ................................................. 38

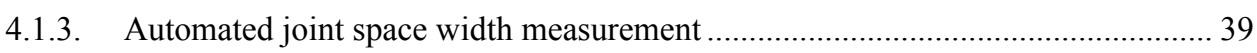

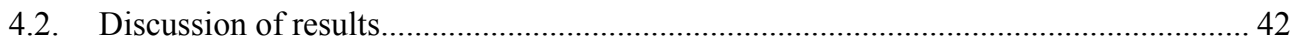

4.2.1. Metacarpal bone loss as biomarker in early rheumatoid arthritis .......................... 42

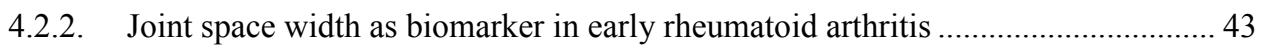

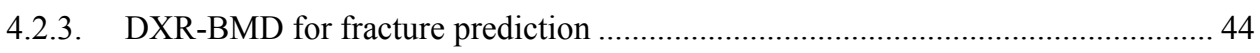

4.2.4. Use of historical radiographs for DXR-BMD in studies .................................. 45

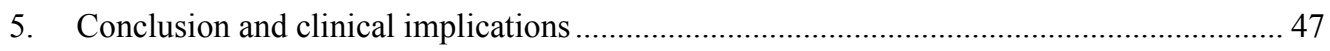

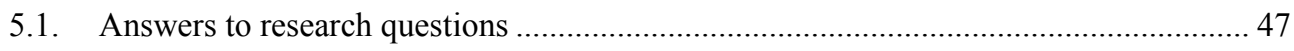

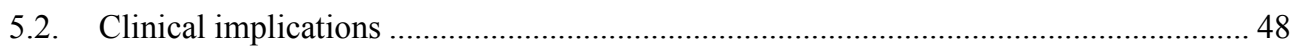

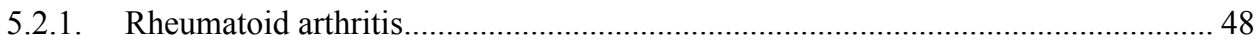

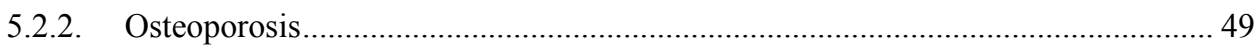

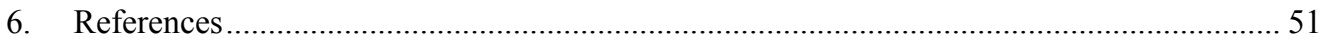

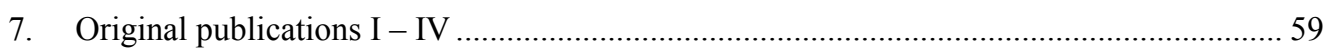




\section{Acknowledgements}

This work has been conducted in collaboration between the Center for Medical Image Science and Visualization (CMIV, www.liu.se/cmiv) at Linköping University and Sectra AB, Linköping, Sweden. It has been funded by Sectra $\mathrm{AB}$ and Linköping University. I wish to express my gratitude to all those who made this work possible:

Anders Persson, my principal supervisor and a constant source for inspiration. My co-supervisors Torkel Brismar, Glenn Haugeberg and Claes Lundström, who through the process have guided me with ideas, critical comments and suggestions. Kristina Forslind, Björn Svensson, Ingiäld Häfström and the BARFOT group and Ronald von Vollenhoven, Hamed Rezaei and the SWEFOT group. Mari Hoff, Alvilde Dhainaut, the PREMIER group, the BeSt group, Steven Cummings and the SOF group, the IMPROVED group, the Leiden Early Arthritis Clinic group and all other research groups and patients, who have contributed to parts of this work not formally part of the dissertation.

I would also like to thank colleagues and staff at CMIV research school, Jakob Algulin and colleagues at Sectra, Monica Nyberg at the Department of Radiology, Linköping University Hospital and colleagues and staff of the Clinical Osteoporosis Research School (CORS).

I would like to thank Torbjörn Kronander at Sectra for making this thesis possible, for inspiration and for commitment in combining business and societal progress. I would also like to thank the Swedish Rheumatism Association, ALF funds, Schering-Plough Sweden, Thelma Zoégas foundation in Helsingborg, Stiftelsen för Rörelsehindrade i Skåne for funding of co-authors and original study cohorts.

Finally I want to thank my family and those around me for your support during this time.

Without all of you, this work could not have been done.

Thank you!

Johan 


\section{List of papers}

\section{Publications included in the dissertation}

Paper I: Does digital X-ray radiogrammetry have a role in identifying patients at increased risk for joint destruction in early rheumatoid arthritis? Forslind K, Kälvesten J, Hafström I, Svensson B; BARFOT Study Group. Arthritis Res Ther. 2012 Oct 15;14(5):R219.

Paper II: Potential sources of quantification error when retrospectively assessing metacarpal bone loss from historical radiographs by using digital X-ray radiogrammetry: an experimental study. Kälvesten J, Brismar TB, Persson A. J Clin Densitom. 2014 Jan-Mar;17(1):104-8.

Paper III: Digital X-ray radiogrammetry of hand or wrist radiographs can predict hip fracture risk -- a study in 5,420 women and 2,837 men. Wilczek ML, Kälvesten J, Algulin J, Beiki O, Brismar TB. Eur Radiol. 2013 May;23(5):1383-91.

Paper IV: Reliability, validity and feasibility of a novel fully automated quantitative method developed for measurement of digital joint space width in inflammatory arthritis. In peer review at the time of writing.

\section{Publications that are not formally part of the dissertation but have been published as part of the work related to this thesis}

Mammography and Osteoporosis Screening - Clinical Risk Factors and Their Association With Digital X-Ray Radiogrammetry Bone Mineral Density. Wilczek ML, Nielsen C, Kälvesten J, Algulin J, Brismar TB. J Clin Densitom. 2014 Oct 4. [65]

Four-month metacarpal bone mineral density loss predicts radiological joint damage progression after 1 year in patients with early rheumatoid arthritis: exploratory analyses from the IMPROVED study. Wevers-de Boer KV, Heimans L, Visser K, Kälvesten J, Goekoop RJ, van Oosterhout M, Harbers JB, Bijkerk C, Steup-Beekman M, de Buck MP, de Sonnaville PB, Huizinga TW, Allaart CF. Ann Rheum Dis. 2013 Nov 27. [45]

Loss of metacarpal bone density predicts RA development in recent-onset arthritis. de Rooy DP, Kälvesten J, Huizinga TW, van der Helm-van Mil AH. Rheumatology (Oxford). 2012 Jun;51(6):1037-41. [49]

Long-term in-vitro precision of direct digital X-ray radiogrammetry. Dhainaut A, Hoff M, Kälvesten J, Lydersen S, Forslind K, Haugeberg G. Skeletal Radiol. 2011 Dec;40(12):1575-9. 
Adalimumab reduces hand bone loss in rheumatoid arthritis independent of clinical response: subanalysis of the PREMIER study. Hoff M, Kvien TK, Kälvesten J, Elden A, Kavanaugh A, Haugeberg G.BMC Musculoskelet Disord. 2011 Feb 27;12:54.

The effect of fat on the measurement of bone mineral density by digital X-ray radiogrammetry (DXR-BMD). Colt E, Kälvesten J, Cook K, Khramov N, Javed F. Int J Body Compos Res. 2010;8(2):41-44.

Short-time in vitro and in vivo precision of direct digital X-ray radiogrammetry. Hoff M, Dhainaut A, Kvien TK, Forslind K, Kälvesten J, Haugeberg G. J Clin Densitom. 2009 JanMar;12(1):17-21. [31]

Adalimumab therapy reduces hand bone loss in early rheumatoid arthritis: explorative analyses from the PREMIER study. Hoff M, Kvien TK, Kälvesten J, Elden A, Haugeberg G. Ann Rheum Dis. 2009 Jul;68(7):1171-6. [46] 


\section{Abbreviations}

$\begin{array}{ll}\text { ACPA } & \text { Anti-citrullinated protein antibody } \\ \text { ACR } & \text { American College of Rheumatology } \\ \text { AUC } & \text { Area under curve } \\ \text { BMD } & \text { Bone mineral density } \\ \text { CRP } & \text { C-reactive protein } \\ \text { DAS28 } & \text { Disease activity score 28 joints } \\ \text { DIP } & \text { Distal interphalangeal joint } \\ \text { DMARD } & \text { Disease-modifying anti-rheumatic drug } \\ \text { DXA } & \text { Dual-energy X-ray absorptiometry } \\ \text { DXR } & \text { Digital X-ray radiogrammetry } \\ \text { HAQ } & \text { Health assessment questionnaire } \\ \text { JSN } & \text { Joint space narrowing } \\ \text { JSW } & \text { Joint space width } \\ \text { MCP } & \text { Metacarpophalangeal joint } \\ \text { MTX } & \text { Methotrexate } \\ \text { PIP } & \text { Proximal interphalangeal joint } \\ \text { QALY } & \text { Quality adjusted life year } \\ \text { QCT } & \text { Quantitative computed tomography } \\ \text { QUS } & \text { Quantitative ultrasound } \\ \text { RA } & \text { Rheumatoid arthritis } \\ \text { RANSAC } & \text { Random sample consensus } \\ \text { RF } & \text { Rheumatoid factor } \\ \text { ROC } & \text { Receiver-operator characteristics } \\ \text { SD } & \text { Standard deviation } \\ \text { SDD } & \text { Smallest detectable difference } \\ \text { SHS } & \text { van der Heijde modified Sharp score } \\ \text { SIFT } & \text { Scale-invariant feature transform } \\ \text { TNF } & \text { Tumor necrosis factor } \\ \text { WHO } & \text { World health organization } \\ & \end{array}$





\section{Introduction}

\subsection{Background}

\subsubsection{Fragility fractures and osteoporosis}

Low-energy trauma and fragility fractures represent a major public health problem. It is estimated that the global incidence of hip fractures will increase from 1.7 million in 1990 to 6.26 million in 2050 [1]. The incidence rate of hip fractures in Sweden is among the highest in the world and of Swedes, who have reached the age of 50, more than 1/5 women and 1/10 men will suffer a hip fracture during their lifetime [2] .

In a review of the economic burden of fragility fractures in the European Union, Hernlund found that in 20103.5 million new fragility fractures were sustained, including 610000 hip fractures, 520000 vertebral fractures and 2.4 million other fractures (e.g. forearm, pelvis, rib and other fractures) [2]. The cost of those fragility fractures were estimated to be $€ 37.4$ billion, excluding the value of lost quality adjusted life years (QALY), with hip fractures accounting for $54 \%$ of the total costs. The deaths directly attributable to these fractures resulted in 26000 life years lost in the EU27 2010. Including the cost of lost QALYs the cost of the fragility fractures occurring in EU27 2010 was estimated at $€ 98$ billion and $€ 4$ billion in Sweden alone. The lowest proportion of costs attributable to pharmacological intervention in EU27 was observed in Sweden (2\%).

The World Health Organization (WHO) defines a fragility fracture as "a fracture caused by injury that would be insufficient to fracture a normal bone...the result of reduced compressive and/or torsional strength of bone" [3].

The disease osteoporosis has been defined and redefined multiple times and by multiple organizations. One internationally recognized definition of osteoporosis is that of the 2000 National Institutes of Health Consensus Development Conference: "Osteoporosis is defined as a skeletal disorder characterized by compromised bone strength predisposing to an increased risk of fracture. Bone strength reflects the integration of two main features: bone density and bone quality. Bone density is expressed as grams of mineral per area or volume and in any given individual is determined by peak bone mass and amount of bone loss. Bone quality refers to architecture, turnover, damage accumulation (e.g., microfractures) and mineralization. A fracture occurs when a failure-inducing force (e.g., trauma) is applied to osteoporotic bone. Thus, osteoporosis is a significant risk factor for fracture, and a distinction between risk factors that affect bone metabolism and risk factors for fracture must be made" [4]. 
In 1994, a WHO work group created a diagnostic definition of osteoporosis [5] based on the number of standard deviations (SD) difference from a normal bone mineral density (BMD) of an individual of the same sex and same ethnicity (i.e. $-2.5 \mathrm{SD}$ ), measured at specific sites and with specific equipment. The definition also included a lower severity category, osteopenia (-1.0 SD). This definition of osteoporosis was specifically intended for use in epidemiological studies but was taken up as standard in clinical practice.

This definition has since been revised to remove dependency on sex and ethnicity, as well as changing measurement sites, but the unclearness of this definition and inclusion of osteopenia may have contributed to the current severe underutilization of measures to reduce the economic and human burden of fragility fractures caused by osteoporosis.

There is a large gap between the number of individuals eligible for anti-osteoporotic medication and the number of people actually receiving treatment. In Sweden, approximately 358000 women and 41000 men are estimated to be eligible for anti-osteoporotic treatment, but only 100000 and 15000 respectively receive treatment [2].

New methods and processes to economically identify individuals who would benefit from antiosteoporotic treatment have the potential to reduce this gap and contribute large economic and human savings to society.

\subsubsection{Rheumatoid arthritis, bone involvement and peri-articular osteoporosis}

Rheumatoid arthritis (RA) is a progressive, chronic, systemic autoimmune disease characterized by inflammation and synovitis in joints [6][7][8]. Peri-articular osteoporosis is one well known characteristic of RA [9]. Elevated levels of pro-inflammatory cytokines mediate osteoclast activation and lead to destruction of cartilage and bone in joints [10].

The RA disease can have severe and debilitating effects on the life of the individual patient and RA does also affect mortality [11]. The prevalence of RA among adults in Europe is around 400500 per 100000 adults, with an incidence rate in the order of 20-40 new cases per year [12].

The societal cost of RA is substantial. The cost of the disease in only Sweden in 2010 was estimated to be $€ 600$ million, of which approximately $60 \%$ was disability pensions and sick leave, $30 \%$ was biological drugs, and inpatient care, outpatient care and conventional drugs made up the remaining $10 \%$ [13].

The most commonly used drugs to treat RA patients are disease modifying anti-rheumatic drugs (DMARDs) including methotrexate (MTX), and corticosteroids. Around 2000, a new class of 
drugs was introduced that was engineered to target specific cytokines or pathways in the RA disease. Several of those new biological drugs, including tumor necrosis factor (TNF) antibodies and receptor antagonists, have been shown effective to inhibit the RA disease. This new category of drugs has, together with improved use of MTX and corticosteroids, contributed to greatly improved patient outcomes over the last decade. Despite clear efficacy though, the cost effectiveness of the biologic anti-rheumatic drugs including TNF blockers is not obvious in all patients, even among patients who did not initially respond effectively in clinical markers to initial treatment with MTX [13][14][15][16].

Numerous quantitative markers are used to guide RA patient management and to assess treatment response; counts of tender and swollen joints, serological markers of rheumatoid factor and anti-citrullinated protein antibodies, inflammation markers such as erythrocyte sedimentation rate or C-reactive protein, patient global health visual analogue scale; as well as more qualitative measures; radiology report, looking at joints with ultrasound, discussing with the patient, doctors global assessment, etcetera.

While patient outcomes have improved greatly in recent years, the therapeutic decision making in RA is still hampered by a lack of effective validated biomarkers. As a result, treatment decision making still has a substantial component of randomness and non-optimal use of resources. New effective biomarkers could improve therapeutic decision making in RA and increase the effect gained from the resources available.

\subsubsection{Measurement of bone mineral density}

\section{Dual-energy X-ray absorptiometry}

Bone mineral density can be measured at a number of different sites and with a number of different technologies. The gold standard for measuring BMD is dual X-ray absorptiometry (DXA) [17]. DXA uses X-ray photons of two different energies to separate muscle and fat from the bone in the X-ray image and estimate the mass of bone mineral per area of projected bone [18]. DXA can be used to measure bone mineral density in many different parts of the body; femoral neck, total hip, lumbar vertebrae, calcaneus, radius, hands as well as user defined regions, for example joints. In fracture risk assessment and diagnosis of osteoporosis, femoral neck BMD is generally considered the most valid measurement site because it has been shown to have the strongest association with hip fractures [19]. While hip fractures are only one of many types of osteoporotic fractures, they make up a significant portion of the total cost of fragility fractures and often lead to severe consequences for the individual [2][20]. 


\section{Quantitative computed tomography}

Another method to estimate BMD is quantitative computed tomography (QCT). QCT of the central skeleton is strongly correlated to BMD measured by DXA when measured at the same site. It is generally considered to be similar to central DXA in fracture risk prediction even though there have not been as many studies using QCT [19]. QCT is available as an additional software for standard CT. Drawbacks of QCT compared to central DXA include a substantial radiation dose to the patient and higher cost. QCT also typically reports bone mineral mass per volume, rather than per projected area as most other BMD devices do. T- and Z-scores may therefore be less comparable to corresponding normalized scores from other BMD devices.

\section{Radiographic absorptiometry}

Radiographic absorptiometry is another method to estimate BMD. In this method, ordinary X-ray equipment is used and a metal wedge is imaged together with the bone to be measured. The bone white level is then compared to the levels of the metal wedge [21][22]. Radiographic absorptiometry is typically performed peripherally, in phalangeal or metacarpal bones, and is generally considered to have weaker association with hip fractures than BMD measures of the femoral neck or total hip.

\section{Quantitative ultrasound}

Another method to estimate fracture risk is quantitative ultrasound (QUS). Unlike BMD measurement methods, QUS devices instead measure properties such as speed of sound and broadband attenuation, and based on those measures calculate an index aiming to reflect fracture risk. QUS is usually measured peripherally, most commonly in the heel. Fracture risk assessment performance appears to vary substantially between different QUS devices [23]. Advantages of QUS include low cost, easy operation and a small device taking up little space. Lack of ionizing radiation to the patient is often also cited as an advantage of QUS, but in clinical practice the effective dose to the patient of most other BMD measurement methods is negligible in relation to the variation in clinical utility between devices.

\section{Digital $X$-ray radiogrammetry}

Digital X-ray radiogrammetry (DXR) is the primary BMD measurement method used and studied in the course of this thesis. Traditional radiogrammetry was first described in the sixties as a method to estimate bone mineral density and bone strength of tubular bones [24]. DXR is an automated version of radiogrammetry working on digital X-ray radiographs of the hand, applying radiogrammetry to measurement regions around the diaphysis of metacarpals 2,3 and 4, Figure 1. 


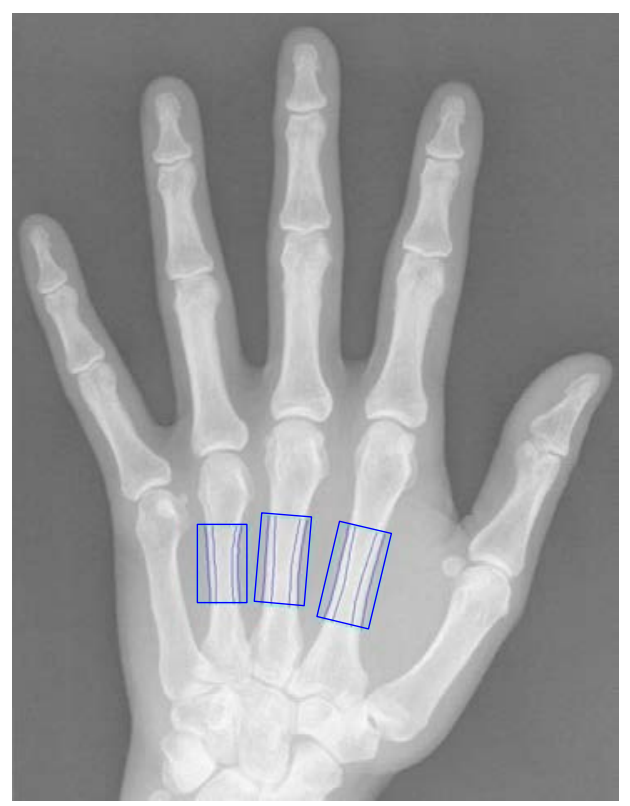

Figure 1. Hand X-ray with the measurement regions for digital X-ray radiogrammetry on metacarpals 2, 3 and 4 marked.

An original version of DXR that operated according to the same principles included also measurement regions in the radius and ulna [25][26] was replaced by the current method in 2001. The current method operates only on the metacarpal bones.

DXR uses a series of correlation methods followed by application of an active shape model [27] to locate the three middle metacarpal bones when placing the measurement regions. In each measurement region, the method applies a tubular bone model. Endosteal and periosteal edges of the cortical bone in the measurement regions along the length of the measurement regions are traced using a Djikstra path tracing based method [28], Figure 2.

The volume $V$ of the cortical bone region is estimated assuming a tubular shape; $V=L \times$ $\left(\pi R^{2}-\pi r^{2}\right)=L \times \pi \times C T \times(W-C T)$, where $L$ is the length of the measurement region, $R$ is the radius of the cylindrical bone, $r$ is the radius of the medullary cavity, $W$ is the width of the bone and $C T$ is the cortical thickness. The cortical bone volume per projected area is then $V P A=V /(L \times W)=\pi \times C T \times(1-C T / W)$. The volume per projected area is calculated individually for each metacarpal measurement region and then combined to a weighted average, $V P A_{\text {comb }}=\left(V P A_{2}+V P A_{3}+0.5 V P A_{4}\right) / 2.5$. 
The bone mineral mass per projected bone area BMD in the measurement region is estimated as $B M D=\rho \times V P A_{\text {comb }} \times(1-P)$, where $\rho$ is the volumetric bone mineral density of cortical bone and $P$ is a porosity estimate, aimed to be the fraction of the cortical bone volume not occupied by bone. $P$ is estimated by a textural analysis of the cortical bone region within the measurement region, based on that cavities in the cortical bone gives dark dents in the pixel profile in the X-ray projection of the region [26].

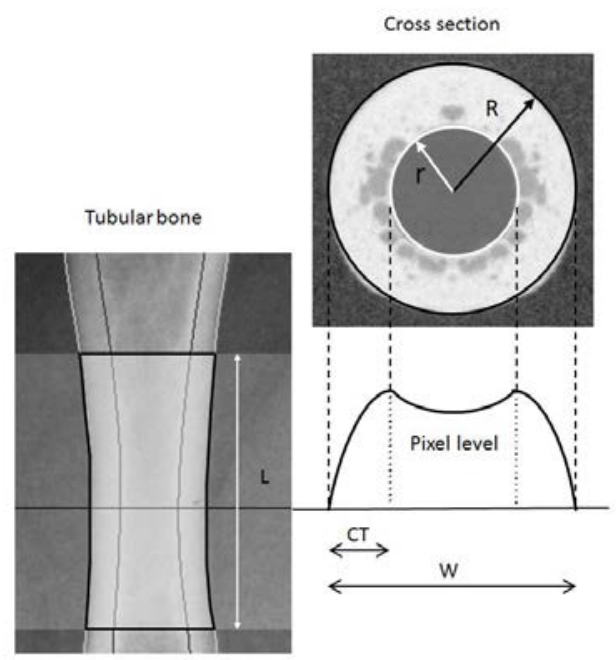

Figure 2. Illustration of principle operation of digital $X$-ray radiogrammetry in a single measurement region (figure printed with permission from Sectra). L: length of measurement region; $R$ : periosteal radius; $r$ : endosteal radius; $C T$ : cortical thickness; $W$ : width of the bone.

The estimated DXR-BMD is compared to a reference database of healthy normal individuals to calculate T- and Z-scores [29].

The DXR method can be applied to hand X-ray images both from general radiology modalities and from mammography modalities. The effective dose of a hand X-ray is negligible, $<1 \mu \mathrm{Sv}$, equivalent to $<8$ hours background radiation in Sweden.

Advantages of the DXR method compared to DXA is that it requires no additional hardware, minimal training and can be combined with mammography for a very efficient screening workflow. The DXR method also has a very high reproducibility [30][31]. 
The primary disadvantage of DXR compared to DXA is that it does not measure the BMD in the femoral neck and has weaker gradient for hip fractures than DXA BMD of the femoral neck.

\subsection{General aims and specific research questions}

The general aims of this thesis were to study the validity of hand bone loss measured with the DXR method as a biomarker in early RA and to investigate DXR performance relative to fracture risk assessment. It was also an ambition to further extend the technique to try to further improve detection of early signs of increased risk for skeletal damage in RA. The thesis was also intended to address the issue of when historical hand X-ray images that were not acquired strictly according to the protocol for DXR images can be used in clinical studies.

The following more specific research objectives were defined in planning the thesis:

1) Under what conditions can DXR-BMD detect increased bone loss in RA?

2) Under what conditions is an increased bone loss of prognostic value in RA?

3) How are the DXR-BMD changes related to other prognostic factors in RA?

4) Under what conditions can DXR-BMD be used to evaluate treatment effect in patients with RA?

5) Can DXR-BMD be used to screen for osteoporosis?

a) in conjunction with mammography?

b) at follow-up of wrist fractures?

6) Can additional image processing, on the same images as used for calculation of DXR$\mathrm{BMD}$, give further improvement on prediction and treatment follow up in RA? 



\section{Material and methods}

\subsection{Paper I}

In an ambition to contribute to the body of knowledge regarding the research objectives 1-4 listed above, the design idea for paper I was to use an existing early RA cohort with existing hand X-ray images at both baseline and follow up visit, estimate metacarpal BMD with the DXR method at both baseline and follow up, and to relate initial changes in metacarpal bone density to radiographic outcome and to other clinical measures of RA activity.

Paper I utilized the BARFOT (Better Anti-Rheumatic FarmakOTherapy) cohort [32]. BARFOT is a multicenter observational study of patients with early RA satisfying the 1987 American College of Rheumatology (ACR) classification criteria [9]. Between 1993 and 1999, 839 patients between ages 18 and 80 were enrolled into BARFOT at 6 study centers. 379 patients had accessible and readable radiographs that fulfilled the technical requirements to be eligible for measurement of DXR-BMD at both baseline and the 1 year visit. Clinical, laboratory and radiographic data was collected during a follow up period of 8 years. During the observation period, patients were treated according to clinical judgment of their rheumatologist, except for 166 patients who participated in a randomized low-dose glucocorticoid steroid study [33].

Radiographic damage was evaluated using the van der Heijde modified Sharp score method [34]. If both hands were available at both baseline and 1 year, the average BMD change of left and right hands was used, otherwise only the BMD change in the hand that was available at both visits was used.

Descriptive statistics of loss of BMD, clinical variables and radiographic score changes were presented. Independency of association to radiographic outcome was tested using multiple logistic regression models.

\subsection{Paper II}

Radiographs obtained solely for visual diagnosis are often not obtained in accordance with the acquisition protocol for DXR. To address the applicability of the method used in papers I, III, IV and many other papers, paper II was designed to investigate when historical X-ray images acquired outside the acquisition protocol for DXR are appropriate for use in clinical studies, and when they are not. 
Repeat radiographs were acquired of a set of 5 cadaver hand phantoms (The Phantom Laboratory, Salem, NY), Figure 3. The phantoms were built from natural human hand bones and cast inside a material with similar X-ray attenuation as hand soft tissue. The phantoms were selected to represent the range of BMD values typically encountered in clinical practice.

The most common deviations from the DXR imaging protocol in cohorts that had previously been processed with DXR were identified and a set of phantom positioning variations were defined to test each of the protocol deviations.

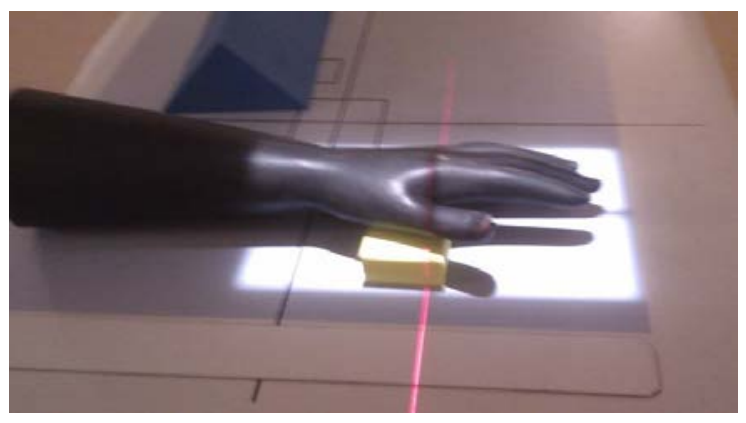

Figure 3. Image acquisition of a cadaver hand phantom. A small block was placed under the base of the thumb, causing different degrees of supination.

The influence of the different deviations from the DXR protocol was evaluated by the variation in mean absolute DXR-BMD, normalized to the average DXR-BMD for each individual phantom specimen when imaged under reference protocol conditions.

\subsection{Paper III}

Paper III addressed research objective 5b. The study design idea was to collect hand radiographs from the digital archives of emergency care hospitals, measure BMD with the DXR method, and follow up hip fracture outcome using the Swedish national registers of hip fracture diagnoses, treatment and death.

The digital archives of three major emergency care hospitals in the Stockholm region were queried for left hand and wrist radiographs. A total of 45,538 radiographs acquired between 1 January 2000 and 31 December 2008 were extracted. Each image was manually reviewed for suitability for BMD measurement by DXR. To be included for further analysis, the radiograph had to visualize the three middle metacarpals sufficiently, be without any fractures, plaster, fixation pins or other foreign material in the measurement regions, and show an acceptable 
positioning of the metacarpals. In total 18,824 hand X-rays from 15,072 patients were considered suitable for DXR analysis.

Hip fracture events were identified through the National Patient Register and the National Cause of Death Register provided by the Swedish National Board of Health and Welfare (ICD-10 codes S72.0, S72.1, S72.2, NFJ, NFB and death). Date of fracture diagnosis, death or study end was used as censoring time. Only patients older than 40 years were selected for further analysis.

Cox regression was used to calculate age-adjusted hazard ratio per standard deviation of DXRBMD (HR/SD). Age adjusted receiver-operator characteristics (ROC) and area under curve (AUC) were calculated and used for comparison to other studies.

\subsection{Paper IV}

The purpose of paper IV was to address research objective 6 and to evaluate the reliability, validity and feasibility of a novel automated method for measurement of joint space width (JSW) in early RA. Within the scope of this thesis, a method for fully automated measurement of JSW of metacarpophalangeal joints (MCP) 2, 3 and 4 and proximal interphalangeal joints (PIP) 2 and 3 was developed and refined. The method automatically locates MCP 2, 3 and 4 and PIP 2 and 3. MCP joints were measured radially over an angular span of $3 \pi / 8$ radians of the metacarpal head and PIP joint spaces were measured in parallel over a $5.5 \mathrm{~mm}$ wide region, Figure 4 . The design and development of the automatic JSW method is further discussed in section 4.1.3.

The predictive value on RA outcome was then tested using a similar approach as in paper I by analyzing an existing early RA cohort. On that material parameter JSW was digitally acquired using the developed software and compared to gold standard, i.e. manual scoring of joint space narrowing.

Paper IV utilized the SWEFOT multicenter early RA randomized controlled treatment trial cohort [35]. Patients enrolled in this cohort had RA according to the ACR criteria [9]. Disease duration was $<1$ year and the patients were disease-modifying anti-rheumatic drugs (DMARD) naïve. All patients were initially started on methotrexate (MTX) monotherapy. Patients, who did not show sufficient response after 3 months, were randomized either to MTX + sulfasalazine + hydrochloroquine or to MTX + infliximab.

Clinical, laboratory and radiographic data was collected during 2 years. Radiographic damage was evaluated using the van der Heijde modified Sharp score method [34]. Patients, who had correctly timed radiographs usable for DXR analysis and had clinical data available, were included in this study of automatic JSW analysis. 


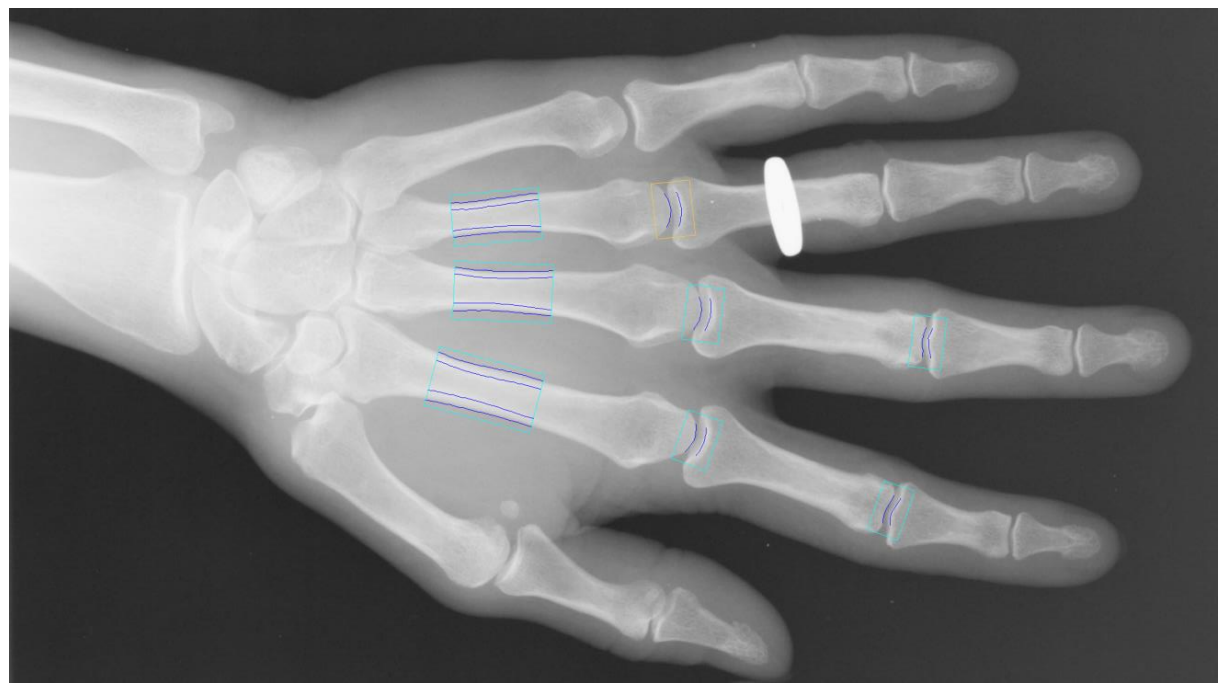

Figure 4. Hand radiograph with measurement JSW and DXR measurement regions indicated. JSW: joint space width; DXR: digital X-ray radiogrammetry.

Short term in vivo reproducibility was evaluated using a separate dataset with 30 healthy volunteers with 3 repeat radiographs each.

JSW was measured at baseline and after 1 year. Only images when DXR-BMD could be measured were analyzed. The JSW measures were aggregated to two scores; average JSW of MCP 2, 3 and 4 (MCP234) and average JSW of PIP 2 and 3 (PIP23). If both hands were available at both baseline and 1 year, the average JSW of left and right hands was used, otherwise only the JSW in the hand that was available at both visits was used.

Descriptive statistics of change in JSW, clinical variables and radiographic joint space narrowing score (JSN) changes were presented. Independency of association to radiographic outcome was tested using multivariate linear regression models.

\subsection{Ethical aspects}

All studies including human subjects were performed in accordance with the ethical standards of the Declaration of Helsinki. All data collection and patient information sheets were evaluated by regional ethics committees prior to the individual studies. 


\section{Summary of results}

\subsection{Paper I: Does digital X-ray radiogrammetry have a role in identifying patients at increased risk for joint destruction in early rheumatoid arthritis?}

The objective of this 8-year-longitudinal study was to explore hand bone loss as a marker for increased risk of joint destruction in patients with early rheumatoid arthritis.

$66 \%$ of the patients had a decrease in DXR-BMD greater than the smallest detectable difference (SDD). Radiographic progression after 2, 5 and 8 years, as defined by the van der Heijde modified Sharp score (SHS) of hands and feet, was associated with decrease in DXR-BMD greater than SDD and decrease of DXR-BMD by tertiles (no/small, moderate and great decrease), Figure 5.

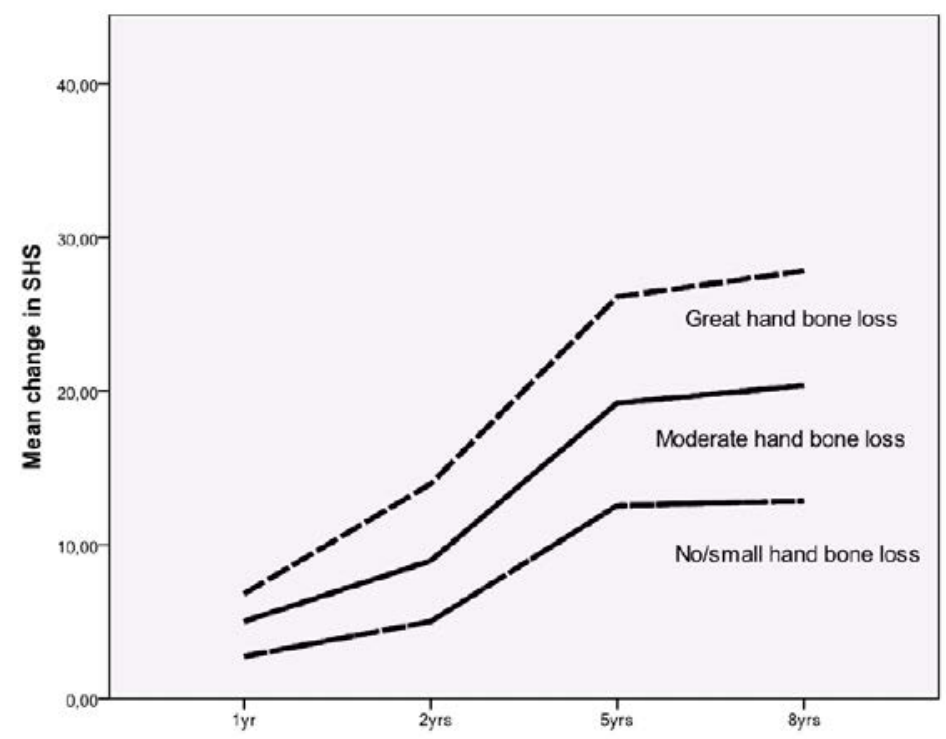

Figure 5. Radiographic progression from baseline to 8 years, stratified by tertiles of decrease in DXR-BMD during year 1. SHS: van der Heijde modified Sharp score.

With permission from Kristina Forslind. Originally published in [Paper I]. 
When change in SHS from baseline to 1 year was included in multiple logistic regression analysis, only change in SHS and anti-citrullinated protein antibody (ACPA) status were independent predictors for progression of SHS from baseline to 2 years. SHS is frequently not available in clinical practice; when change in SHS was not included in the multiple logistic regression model decrease in DXR-BMD, erosions at baseline, ACPA status and number of swollen joints were independent predictors for progression of SHS at 2 years.

Decrease in DXR-BMD was not significantly associated with disease activity score (DAS28) remission after 2,5 and 8 years.

\subsection{Paper II: Potential sources of quantification error when retrospectively assessing metacarpal bone loss from historical radiographs by using digital $\mathrm{X}$-ray radiogrammetry: an experimental study.}

The average DXR-BMD of the 5 cadaver hand phantoms was $0.475 \mathrm{~g} / \mathrm{cm}^{2}$. All the evaluated image acquisition protocol deviations except voltage affected the measurement of DXR-BMD significantly, Table 1, Figure 6.

When the same image acquisition protocol deviation was repeated for the same specimen, the within-specimen reproducibility was smaller than $2 \mathrm{mg} / \mathrm{cm}^{2}$ for all protocol deviations.

For all image acquisition protocol deviations except voltage and reduced exposure, the magnitude of the effect of the protocol deviation on the measured DXR-BMD was significantly dependent on the cadaver specimen. 
Table 1. Impact of deviation from DXR image capture protocol on DXR-BMD. Mean absolute DXR-BMD normalized to the average DXR-BMD for the corresponding phantom specimen under DXR protocol conditions and p-values for the two null hypotheses that variance and mean respectively of measurements normalized to the average DXR-BMD for the corresponding phantom specimen are the same as under DXR protocol conditions.

\begin{tabular}{lccc}
\hline Variatio & $\begin{array}{c}\text { Mean absolute } \\
\text { deviation in } \\
\text { DXR-BMD } \\
{\left[\mathrm{mg} / \mathrm{cm}^{2}\right]}\end{array}$ & $\begin{array}{c}\text { Variance } \\
\text { equal DXR } \\
\text { protocol } \\
\text { p-value }\end{array}$ & $\begin{array}{c}\text { Mean equal } \\
\text { DXR } \\
\text { protocol } \\
\text { p-value }\end{array}$ \\
\hline DXR protocol & 0,7 & - & - \\
Voltage $(52 \mathrm{kV})$ & 3,4 & 0.66 & 0.58 \\
Exposure $(2.0 \mathrm{mAs})$ & 3,2 & 0.004 & $<0.001$ \\
Lateral displacement $6.6 \mathrm{~cm}$ & 6,2 & $<0.001$ & 0.28 \\
Supination $1 \mathrm{~cm}$ & 9,2 & $<0.001$ & $<0.001$ \\
Supination $2 \mathrm{~cm}$ & 6,1 & $0.057^{\mathrm{a}}$ & $<0.001$ \\
Extension of the wrist $8^{\circ}$ & 2,9 & $<0.001$ & 0.27 \\
Lateral displacement $6.6 \mathrm{~cm}+$ rotation $6^{\circ}$ & 7,4 & $<0.001$ & 0.089 \\
Lateral displacement $6.6 \mathrm{~cm}+$ supination $1 \mathrm{~cm}$ & 9,1 & $<0.001$ & $<0.001$ \\
Edge enhancement & & & \\
\hline
\end{tabular}

a 5 repeats in a single phantom.

Originally published in [Paper II]. 


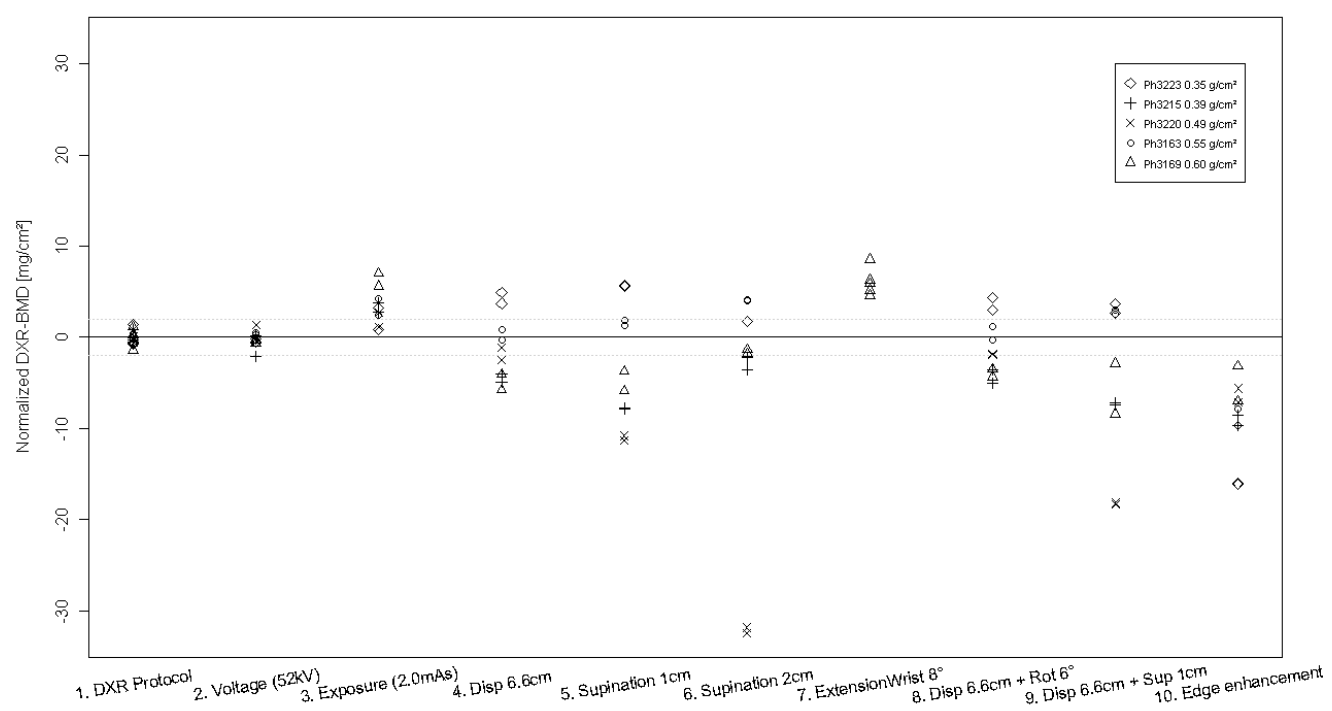

Figure 6. Normalized DXR-BMD by DXR acquisition protocol deviation.

Originally published in [Paper II].

\subsection{Paper III: Digital X-ray radiogrammetry of hand or wrist radiographs can predict hip fracture risk--a study in $\mathbf{5 , 4 2 0}$ women and 2,837 men.}

5,420 women and 2,837 men met the inclusion criteria of the study. The average age was 60.5 years in women and 57.8 years in men. The average observation period was 3.3 years. During the total observation period of 27,072 person years 122 patients suffered a fracture, 89 women and 33 men.

The age adjusted AUC for DXR-BMD to predict hip fracture within the observation period was 0.89 in women and 0.84 in men when evaluating the whole population and 0.83 and 0.80 respectively when restricting to only the 55-85 year age span.

The age adjusted hazard ratios for hip fracture during the observation period by DXR-BMD Tscore in women and men in this cohort are shown in Figure 7. The hazard ratio per standard deviation for hip fracture was 2.5 and 2.1 respectively for women and men in the whole cohort and 2.3 and 2.0 respectively in the 55-85 year age group. 


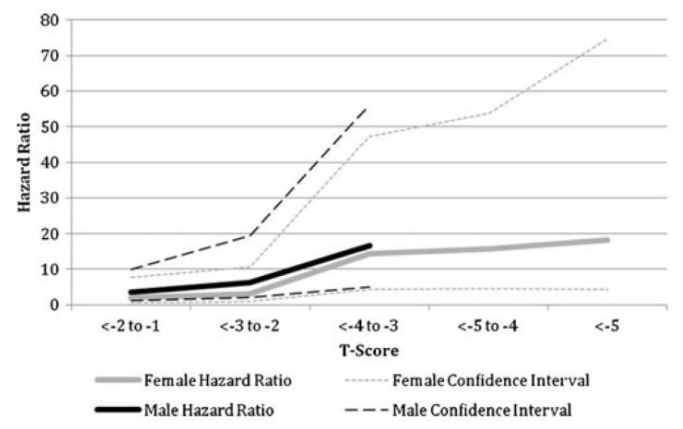

Figure 7. Hazard ratio for hip fracture by DXR-BMD T-score. T-score > -1 used as baseline risk.

With permission from Michael Wilczek. Originally published in [Paper III].

\subsection{Paper IV: Reliability, validity and feasibility of a novel fully automated quantitative method developed for measurement of digital joint space width in inflammatory arthritis.}

Out of the 487 patients in the SWEFOT trial, 119 both had radiographs applicable for DXR processing from both baseline and 1 year follow up available and had the applicable clinical data available. Of those, 98 patients had usable radiographs of both hands at both time points. The primary cause for exclusion of cases was that baseline and follow up X-ray images had been acquired with different imaging technologies.

Of the 119 cases with radiographs applicable for DXR processing, there was no case where MCP234 JSW could not be automatically measured successfully at both baseline and 1 year in at least one of the hands. The automatic measurement of PIP23 JSW failed for both hands at at least one of the time points for 2 of the 119 cases and a change rate of PIP23 JSW could not be calculated for those two cases.

The mean (SD) change of MCP234 JSW from baseline to 1 year (Ch1YMCP234) was -0.020 (0.070) $\mathrm{mm}$ and corresponding mean (SD) change for PIP23 JSW (Ch1YPIP23) was -0.013 $(0.054) \mathrm{mm}$. Short-term in vivo reproducibility in the 30 healthy volunteers was $1.4 \%$ for MCP234 JSW and 1.6\% for PIP23 JSW, corresponding to an SDD of $0.062 \mathrm{~mm}$ for MCP234 and $0.041 \mathrm{~mm}$ for PIP23 JSW. 
In univariate linear regression, Ch1YMCP234 was significantly associated with 1 year change in JSN (Ch1YJSN) while Ch1YPIP23 was not significantly associated to Ch1YJSN.

In a post-hoc test, a univariate linear regression with baseline JSN as dependent variable and baseline MCP234 JSW as explanatory variable was highly significant, $p=0.006, \beta=-67$. The model was not improved when adding baseline PIP23 JSW.

In multivariate linear regression for Ch1YJSN with stepwise elimination of the factor with highest p-value, $>0.05$, only ESR survived and all other tested risk factors; age, gender, ACPA, RF, C-reactive protein (CRP), DAS28, HAQ, presence of erosions at baseline (SHS $>0$ ), 1 year change in DXR-BMD (Ch1YBMD), Ch1YMCP234 and Ch1YPIP23 were eliminated in the stepwise elimination. The highest observed adjusted $\mathrm{R}^{2}$ was achieved by a model, obtained about halfway through the elimination, including ESR, RF, DAS28, age and MCP234 JSW. In the corresponding elimination for change in JSN from year 1 to year 2 only Ch1YMCP234 survived the elimination.

No significant difference in Ch1YMCP234 was observed between the treatment groups of the SWEFOT trial. 


\section{Discussion}

\subsection{Methodological issues}

\subsubsection{Study design}

To address the defined research questions, a strategy of collecting existing radiographs that had already been acquired for other purposes or studies was adopted and used for papers I, III and IV. This approach itself highlighted another research question; under what imaging parameter variations can pre-existing hand X-ray images be used for DXR-BMD measurement in clinical studies? This additional question was addressed in paper II.

Both paper I and paper IV were based on pre-existing longitudinal early RA cohorts. This retrospective design made the studies feasible economically and time wise, but also caused several limitations. Only data that was collected in the original cohorts was available for the studies. Ideally, data would have been available that would have enabled to make the studies to as well as possible mirror the way the methods would potentially be used in clinical practice. For example, based on the reproducibility of DXR-BMD and the observed levels of DXR-BMD loss in these and other previously analyzed early RA cohorts, a reasonable compromise between clinical usability and measurement accuracy would have been to use a follow up time of around 3 months, rather than the 12 months available in paper I and paper IV. This limitation was less critical for JSW in paper IV since that study was more explorative and less was known of JSW changes in early RA in advance of the study.

Both paper I and paper IV studied longitudinal changes over time, of BMD and of JSW respectively. When measuring change, the level of reproducibility is critical as it determines the accuracy of the change rate estimate. To achieve the level of reproducibility specified by the manufacturer, the same type of X-ray equipment, exposure parameters and hand positioning must be used at both time points. Since the X-ray images in the study cohorts used had already been acquired, these requirements were not taken into account when the image acquisition was originally done. A consequence, both of using existing studies and of the long time between the baseline and the follow up radiographs, was that many patients had been imaged by different modality models at baseline and follow up images. Many had the baseline image made with analogue X-ray and the follow up image with digital X-ray, or images made with digital X-ray but then printed on film. In both these cases the error level that could potentially be systematically introduced was considered large and those patient cases were discarded. 
Also the patient cases that were retained had non-consistent exposure parameters and positioning that is avoided in prospective imaging acquired for digital analysis. In order to compare the level of reproducibility in the various study cohorts to each other, the variation in difference between baseline and follow up images in average outer metacarpal width in individuals was measured. The outer metacarpal width was selected because it was thought to be relatively stable over the time frame measured, would be affected by many of the acquisition protocol deviations that would affect DXR-BMD and it was also an easily assessable parameter using the DXR software. The intra-individual variation in metacarpal width was considerably larger in the cohorts of paper I and paper IV than in prospectively collected cohorts but it was similar to several other retrospectively collected cohorts (data not shown). However, this indicates that the estimation of BMD change in retrospective studies (paper I and IV) probably is considerably less accurate compared to prospective studies where acquisition parameters can be held consistent.

Paper II was designed to guide the design and interpretation of clinical studies where DXR-BMD measurements are based on pre-existing X-ray images. The DXR-BMD algorithm assumes and checks that the acquisition parameters and positioning is held constant at specified levels. A number of acquisition variations have been investigated before [36], but several of the parameters that in our experience commonly vary between baseline and follow up images in historical cohorts have not previously been investigated.

Edge enhancement and other forms of image post processing are commonly used to improve digital images. These are highly relevant for the DXR-BMD reproducibility. However, the effect of edge enhancement on DXR-BMD can be expected to be strongly dependent on the actual implementation and an evaluation of a single implementation of edge enhancement may therefore not be generalizable.

We choose to use anthropomorphic hand phantoms based on cadaver bones for this study rather than using human subjects. While this had the advantage of not exposing human subjects to additional radiation, it also caused a number of limitations. The phantoms were rigid while the bones in the human hand are likely to move or twist slightly relative to each other for example at supination or extension. The extension of the wrist variation was also not possible to perform with 4 of the phantoms due to their shape and rigidity.

Another limitation is that only a relatively small number of phantom specimens were available. The study showed that different specimens were affected to different degrees by several of the positioning variations, Figure 6 . Thus it would have been desirable with a larger sample of specimens or individuals to achieve a more accurate estimation of the significance of the different imaging variations. 
For paper III, a new cohort was collected from existing left hand X-ray images. Three large emergency care hospitals in the Stockholm region were selected based on feasibility. Outcome data was then collected from national registers. This strategy enabled this study with a large number of patients and patient years to be carried out relatively swiftly and with moderate use of resources. It did however also lead to several limitations.

The amount of information available about each patient was limited. Because the cohort was collected retrospectively, we did not have the opportunity to collect additional risk factors, e.g. those that are included in FRAX. We also did not have the opportunity to do central DXA measurements for comparison. The lack of FRAX and DXA-BMD data makes the comparison of the predictive performance more difficult. This is because AUC and relative risk/SD are influenced not only by the predictive value of the method, but also by the distribution of the cohort.

We also lacked information about the reason why a patient had their hand X-ray made. That poses limitations for what subanalyses can be made and what generalizations that can be made.

Hand-dominance might affect the measurements due to different load. In this retrospective study it was not possible to obtain information about hand dominance. To minimize the influence of uneven loading we therefore decided to collect only left hand images. In Sweden approximately $90 \%$ are right handed, so thus a large majority of the cases had their non-dominant hand analyzed.

It is likely that some of the patients included in the study were already receiving treatment for reducing incidence of fracture. That information was not available at the time of the study. Eventual treatment for osteoporosis would however cause an underestimation of the predictive value of DXR-BMD in this study.

Due to the fact that the X-ray images in paper III had been acquired for other purposes and the DXR protocol was not used in the images acquisition, the accuracy of the DXR-BMD measurements was suboptimal. However, based on the results of paper II, as well as previous studies and computer simulations of the impact of measurement inaccuracy on fracture risk gradient, this slight inaccuracy should not have significantly influenced the results of the study.

While papers I, III and IV had retrospective designs, the hypotheses for the different studies were set as for prospective studies; define research question, define statistical tests, measure $\mathrm{BMD} / \mathrm{JSW}$, perform statistics, analyze the results. 


\subsubsection{Representativeness of the study populations}

The best practice for management of early RA patients is ever evolving. There has been a shift during the last 20 years to better use of methotrexate, corticosteroids and new biological drugs, all contributing to a dramatic improvement of patient outcomes. There has also been a shift in how and when the RA diagnosis is made. This poses limitations for generalizing findings of studies between different populations, treatment strategies and management guidelines.

About half of the cohort in paper I were participants in a randomized controlled trial for addition of low dose corticosteroids to MTX whereas the treatment of the remainder of the cohort was decided by observational, best clinical judgment by the treating rheumatologist. All patients were included before biological drugs had been introduced to the market. The inclusion criteria included fulfilling the ACR 1987 criteria for RA. The population thus represents a relatively high-risk group at baseline compared to today's less strict diagnosis criteria [37]. While on average being relatively intensively and well treated for their time, management of new RA patients today is even more intensive, in particular for patients who are non-responders after a number of months, where additional treatment options are available today. It could be reasonable to expect that in clinical practice today, average rates of bone loss as well as average rates of radiographic damage scores would be lower than observed in paper I. As a comparison, the patients in paper IV participated in a randomized controlled trial on patients with early RA. After six months patients who had not responded satisfactory to MTX monotherapy were randomized to either biologic treatment or intensified traditional DMARD therapy. The therapy given during the first year of that study probably better reflects the current clinical practice in Sweden for patients with recently diagnosed early RA than the treatment described in paper I.

The paper III cohort was collected in an opportunistic manner with little control over or information about the subjects. Hand images were extracted from digital archives based on database examination codes. If there was any relevant examination code that we failed to identify, or if any specific hand examination type did not correctly and systematically get a specific code, cases from those examination types would not have been included in the study.

There were a few X-ray labs that were configured with a very strong level of edge enhancement. As previously described, the influence from a very strong edge enhancement is not possible to evaluate due to the great number of possible edge enhancement algorithms. Such radiographs were therefore excluded. This might have cause a bias, because patients might have been imaged at different labs depending on referral indication. 
Retrospectively analyzed, there was a difference in referral indication between the three emergency hospitals. Södersjukhuset appeared to be dominated by forearm fracture cases whereas Karolinska Solna and Karolinska Huddinge appeared to have had more varied indications, including more rheumatic patients. Rheumatic patients are more likely to have already been assessed for excessive fracture risk and therefore also have current anti-osteoporotic treatment. In hindsight, using only radiographs from Södersjukhuset might have increased the generalizability to that extent that it would have been worth the reduction in patient numbers. A follow up study is ongoing, where a subanalysis with cases recruited only from Södersjukhuset will be analyzed to validate the robustness across indications.

However, Södersjukhuset supplied the highest number of cases to the cohort in paper III and the indication for referral in the cohort as a whole appeared to be dominated by potential fracture. The study could be expected to be reasonably representative for patients over 40 years of age attending an emergency hospital having a hand X-ray made.

\subsubsection{Automated joint space width measurement}

RA radiographic damage is characterized both by erosions and narrowing of the joint area in the small joints of hands and feet. Erosions and joint space narrowing are often scored separately [34]. Experience from clinical trials has indicated that while loss of DXR-BMD has a strong association with progression of total radiographic damage score, the association may be stronger to the erosions component and weaker to the joint space narrowing component.

Hence, we set the hypothesis that the loss of DXR-BMD + reduction in joint space width in some of the joints might be a stronger biomarker of radiographic damage in RA than loss of DXR-BMD alone. If implemented to be evaluated automatically at the same time as processing DXR-BMD, the obtained JSW parameter could potentially increase the sensitivity at a very limited additional cost. Several other research groups have made approaches for automatic or semiautomatic joint space measurements in the past [38] with moderate success so far. Within the scope of this thesis, a method for fully automated measurement of joint space width of small joints in the hand to be automatically applied at the same time as DXR-BMD measurements was developed.

The DXR software uses an active shape model based approach for image registration to locate and validate the three middle metacarpals in a hand X-ray image [26]. This image registration functionality was reused and used as initialization vector. Two different approaches for locating small joints were implemented and tested. 

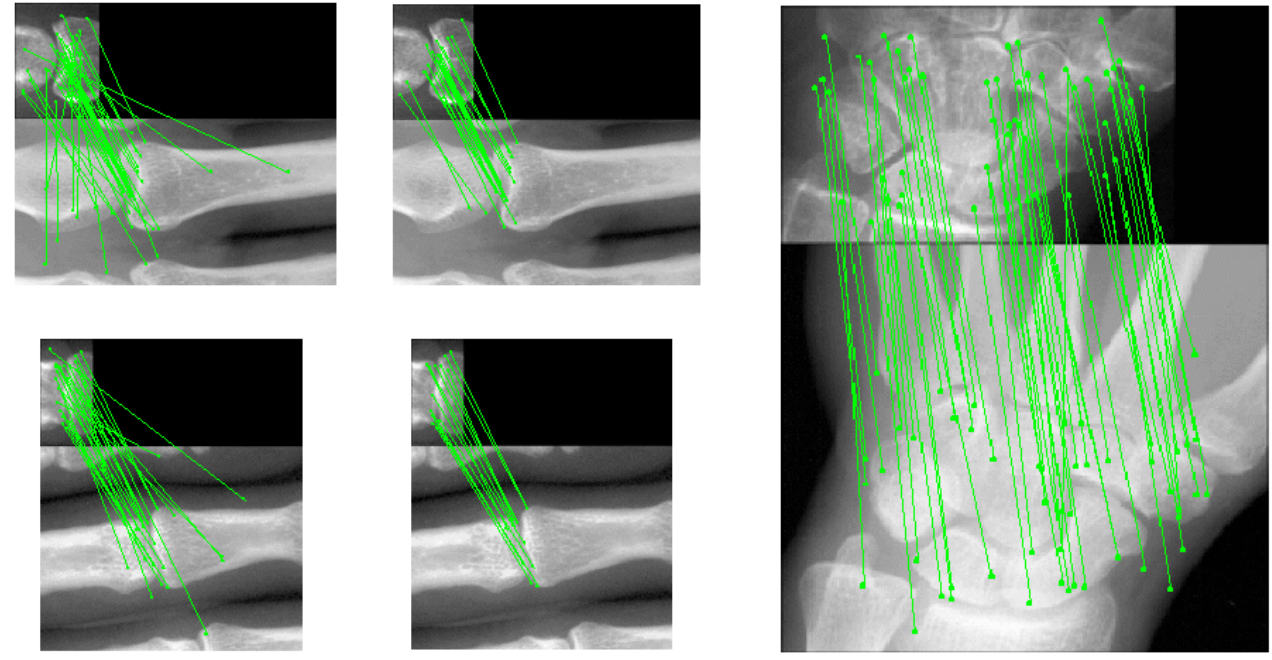

Figure 8. SIFT+RANSAC based approach to joint localization.

One approach was based on the scale-invariant feature transform (SIFT) [39] and the random sample consensus (RANSAC) [40]. Limitations on scale, rotation and localization were introduced based on known variation in hand anatomy and location of other joints in the same index.

A strength of patch-based methods such as SIFT is robustness towards clutter in the image, for example rings, erosions, fractures and deformities. The SIFT-based approach was tested for MCP, PIP and distal interphalangeal (DIP) joints in digits 2, 3 and 4 of 159 hands with a single set of template joints, Figure 8, Figure 9. The failure rate was $0.42 \%, 1.26 \%$ and $2.1 \%$ for MCP, PIP and DIP joints respectively. That failure rate would be inconvenient if used in a clinical workflow. In particular the DIP joints were clearly sensitive to the level of extension of the joint. 


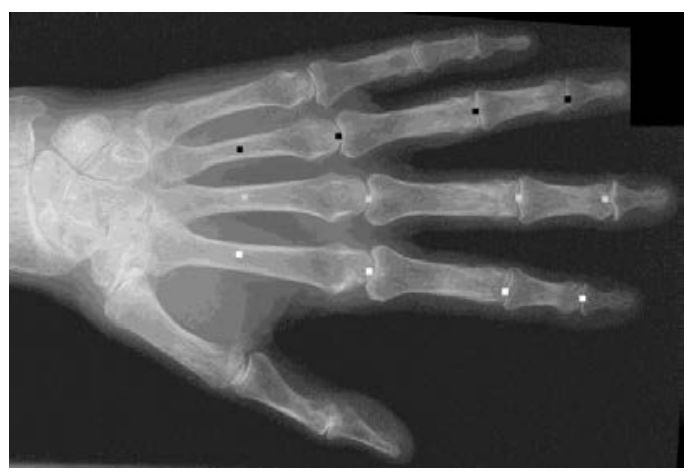

Figure 9. Metacarpophalangeal, proximal interphalangeal and distal interphalangeal joints of digits 2, 3 and 4 located by SIFT+RANSAC method.

Another approach that was explored was image registration based on fitting the texture of individual bones to a training set. The implementation was based on active appearance models as described by Cootes et al [41]. Within the DXR software code base there was preexisting code and models that could be reused for this purpose. With this method, a template for each bone is allowed to deform its shape and texture to a limited degree.

We hypothesized that the difference between the deformed model and the actual hand might be useful for detecting erosions in the joint area. After some experimentation however, we concluded that model difference alone with this approach might be insufficient to reliably quantify erosions. The texture was highly dependent on even small variations in rotation, projection and shape, Figure 10. It could be that fitting to a projected 3D model instead with requirement on continuous surfaces on the model could be a possible approach for erosion scoring. We did not pursue erosion quantification further in this project.
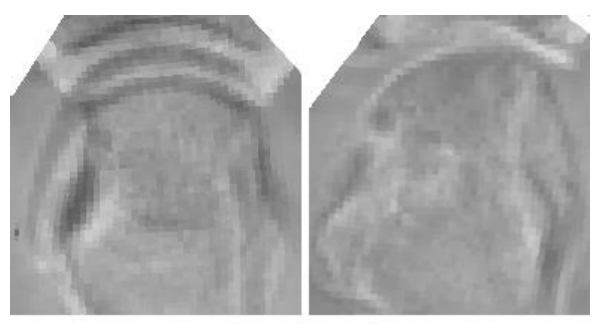

Figure 10. Difference between deformed model texture and image texture of two metacarpal heads. There are several erosions in the right image but they do not stand out clearly in relation to other deviations from the model. 
For measurement of joint space width of metacarpophalangeal joints, a radial joint model over $3 \pi / 8$ radians in the direction of the proximal phalangeal bone was fitted iteratively. Joint space width of interphalangeal joints was measured as an average over a width of $5.5 \mathrm{~mm}$ in the center of the joint. The interphalangeal joint analysis was a further development of the semi-automatic method used in [42] and [43].

Experimentation with robustness, reproducibility and association with JSN was carried out using a small dataset separate from paper IV. After experimentation, it was decided that limiting the JSW measurements to metacarpophalangeal joints (MCP) 2, 3 and 4 and proximal interphalangeal joints 2 and 3 and using the texture based registration method showed promise as a balance between robustness, reproducibility and association with JSN and this approach was selected for paper IV.

There has recently been great progress made in neural networks and deep learning methods that have dramatically reduced failure rates in computer vision systems [44]. Such methodology could potentially be used for automatic and robust JSN scoring, as well as for robustly locating of carpal joints and automated erosion scoring.

\subsection{Discussion of results}

\subsubsection{Metacarpal bone loss as biomarker in early rheumatoid arthritis}

A number of other studies by different research groups have studied DXR-BMD changes in different early RA patient populations, with different inclusion criteria, disease severity and treatment management [45][46][47][48][49][50][51][52][53][54][55][56][57][58][59][60][61]. There has been strong consistency in the association of elevated rate of DXR-BMD decrease and the progression of radiographic damage scores both on group and individual levels. Individuals and study populations with greater levels of disease severity and less intensive management have suffered more bone loss and more X-ray damage score progression than populations with lower baseline severity and more intensive treatment. In those trials that included randomized treatment groups, the group with the more potent treatment on average also suffered less metacarpal bone loss.

On the individual level, the findings have also been consistent across different settings with a theory that excessive osteoclast activation contributes both to increased rate of bone loss in the metacarpals and to development of erosions in joints as measured by manual radiographic scoring methods in hands and feet. 
Paper I was consistent with the findings of previous and later studies and confirmed the association of metacarpal bone loss and radiographic progression in this pre-biologic era cohort of early RA patients. The association to radiographic progression was independent of other markers for disease activity and risk of future progression commonly available in clinical practice.

If progression of radiographic score during the first year was included as an explanatory variable, only ACPA status remained as an independent risk factor for radiographic progression to year 2 , 5 and 8. Radiographic score is however not often available in clinical practice due to cost and lack of trained readers. Furthermore, a follow up time of 12 months is impractical in clinical practice. To be able to help swiftly guide therapeutic decisions, a biomarker should be able to determine whether an early RA patient is responding satisfactorily to a treatment or not within 36 months. Radiographic scoring methods have relatively low reproducibility in relation to the rate of progression. This reduces accuracy of change rate estimations when measured over short time periods. Traditional radiographic score is also often zero during the early phases of the disease.

\subsubsection{Joint space width as biomarker in early rheumatoid arthritis}

In paper IV, we explored if adding image processing of the radiographs, additional to the calculation of change in DXR-BMD, could increase the association to joint space narrowing component of the radiographic progression score. After informal testing during the development of the image analysis, we assumed that DIP joints JSW, as well as some PIP joints, were likely to detract more from overall performance than it would add. These parameters were therefore not investigated further.

In the study, change in MCP joints JSW was associated to progression of JSN score of hands and feet. The association was in line with our expectations, being weak but still comparable to the best of the clinical risk factors normally available in clinical practice. There were several reasons for us expecting the association to be weak; the accuracy of JSN score change is relatively low, a great intra-patient variability in joint destruction, and a low number of joints included in the scoring method (6 joints), while a greater number were included in the reference method (42 joints).

To our surprise the JSW change in the 4 PIP joints over 12 months did not show any association at all to the change in the 42 joints JSN score. Apparently the limitations mentioned previously made the power of our study too low to detect any association. 
The image analysis implementation showed to be sufficiently robust to be usable in a clinical workflow. This is in contrast to other previous efforts at fully automated joint space width measurements [38]. When coupled with DXR-BMD measurements in the RA clinical workflow the developed JSW measurement would provide the rheumatologist an additional biomarker without requiring any extra human labor.

Based on observed reproducibility and magnitude of observed MCP JSW changes in paper IV, it appears that JSW requires longer follow up times than DXR-BMD to be accurate and relevant on an individual level. When measured in $6 \mathrm{MCP}$ joints and appropriate image acquisition protocols are used a reasonable follow up time could be 4-6 months.

While easy and potentially at low added cost if done opportunistically at the same time as DXRBMD processing, it is a question whether the relatively small added prognostic accuracy by the MCP JSW is worth the added complexity of having one more biomarker to relate to, or if a more comprehensive image analysis of more joints should be developed before introducing JSW as an additional biomarker in clinical practice.

\subsubsection{DXR-BMD for fracture prediction}

To the author's knowledge, there had previously been four studies by three separate research groups evaluating DXR-BMD with hip and/or vertebral fracture end points [62][63][64]. All four previous studies concluded that DXR-BMD predicts fractures to a similar degree as forearm or calcaneal DXA, whereas femoral neck DXA predicts hip fractures to a superior degree and predicts non-hip major osteoporotic fractures to a similar degree as other BMD sites including DXR-BMD.

In the paper III study, higher age-adjusted hip fracture risk gradient and higher ROC AUC was observed than that reported for the patient cohorts in the earlier studies. We believe that the differences observed may be due to difference in patient characteristics. The patients included in our study may have had a lower baseline risk for hip fractures. They were on average younger but came from a greater age range and were already visiting the hospital for a reason, in many cases a wrist fracture.

Looking at relative hazard ratio by DXR-BMD T-score (Figure 7), it is clear that the relation is not exponential as assumed by HR/SD regression. HR/SD is therefore dependent on the distribution of BMD within the study population and thus the inclusion criteria. Extremely low BMD T-scores may be more common in the hands than in the central skeleton due to rheumatoid arthritis, which could possibly affect comparisons. 
The findings of paper III is in accordance with the four previous studies with hip or spine fracture endpoints [62][63][64] and confirms the ability of DXR-BMD to identify individuals at increased risk for fracture. Unlike the other studies, this study does represent a specific setting where BMD can be measured opportunistically when a hand X-ray has already been acquired.

\subsubsection{Use of historical radiographs for DXR-BMD in studies}

DXR has for a long time been used to estimate metacarpal BMD and change of metacarpal BMD in historic cohorts where images were not acquired according to the DXR image acquisition protocol. In those studies, a level of validation of sufficient accuracy of bone loss measurements in the specific cohort has been provided by the significance of the findings, e.g. showing expected significant difference in bone loss between randomized treatment groups or showing significant gradient of fracture incidence. The influence of deviations from defined image acquisition parameters on the obtained DXR-BMD has however not been clear. This has in particular been a concern for studies evaluating longitudinal change of BMD, an approach common in studies on RA patients.

In paper II, the impact of a number of DXR protocol deviations that are common in historical radiographs was quantified. When planning studies with historical images, the findings in that study can help guiding which types of changes between baseline and follow up images that can be tolerated and which types of changes that are not acceptable, depending on expected effect size. Another important finding of that study was that none of the evaluated capture variations would substantially affect the outcome in studies of fracture risk based on absolute level of DXR-BMD. 



\section{Conclusion and clinical implications}

\subsection{Answers to research questions}

A number of specific research questions were defined when outlining this thesis project, listed in the introduction section.

1) DXR-BMD can be used to detect increased bone loss in RA when the reproducibility error is substantially less than the effect size. The reproducibility error under several non-protocol conditions common in historical cohorts are listed in paper II. This and other studies have indicated the reproducibility error for DXR-BMD under protocol conditions to be in the order of $1-3 \mathrm{mg} / \mathrm{cm}^{2}$. Paper I and other studies indicate that effect sizes from about $6 \mathrm{mg} / \mathrm{cm}^{2} / \mathrm{month}$ and down are common. Studies with down to 4 months follow up time have been published with a significant effect measured with DXR-BMD [45].

2) In early RA patients, detection of increased metacarpal bone loss adds prognostic information independently of age, sex, DAS28, ACPA and presence of erosions on $\mathrm{X}$-ray at baseline. Bone loss does not add additional prognostic value if 12 months change in radiographic score is available.

3) Changes in DXR-BMD are associated with DAS28, ACPA and progression of radiographic score. While cross-sectional studies have shown associations between age and sex and the absolute level of DXR-BMD, no strong association has been observed between change in DXR-BMD and age or sex in RA patients.

4) See 1-3). The difference in average DXR-BMD effect size between treatments has been evaluated in a number of randomized controlled trials with different patient characteristics and settings.

5) a) The workflow implications of applying DXR-BMD in conjunction with mammography screening were evaluated in [65] which is not formally part of this dissertation but was published as part of this work. Adding a DXR-BMD measurement to the mammography screening examinations had minimal impact on the workflow and did not reduce the number of mammography exams done per day. 
b) Low DXR-BMD was a strong predictor for incidence of hip fracture in individuals who had hand X-rays made in three major emergency care hospitals in the Stockholm region. Workflow implications of sending wrist fracture images and managing reports were not evaluated in this $\mathrm{PhD}$ project.

6) Automatic measurement of joint space width in metacarpophalangeal joints 2, 3 and 4 as implemented in this project does add a statistically significant but small independent value in prediction and treatment follow up in early RA. Joint space width of proximal interphalangeal joints 2 and 3 as implemented in this project did not add any additional value.

\subsection{Clinical implications}

\subsubsection{Rheumatoid arthritis}

The results in this thesis and other studies that have been published as part of this work may be of interest and importance for healthcare planning and the management of RA.

Currently therapeutic decision making in RA relies heavily on clinical markers of disease such as joint counts, inflammation markers and ACPA/RF as well as qualitative radiology reports. All currently existing markers are however limited in effectiveness and sensitivity, in particular in relation to progression of joint damage. At the same time the cost of drugs in RA has increased to significant levels. A number of new markers, including magnetic resonance imaging, ultrasound and metacarpal bone loss rate, have been proposed to complement current clinical markers to further improve effectiveness, sensitivity to rate of joint damage and improve therapeutic decisions.

Our results concur with a large number of independent studies; DXR-BMD bone loss rate measured over periods down to 4 months consistently come out as an independent marker for increased risk for radiographic progression. DXR-BMD loss rate as a quantitative objective biomarker can thus improve the accuracy of early RA patients' prognoses and accuracy of treatment efficacy follow up.

Automatic joint space width as implemented in this project is in the author's opinion not yet effective enough to warrant application in clinical use. 


\subsubsection{Osteoporosis}

The results of this thesis may also be of interest and importance for healthcare planning in the field of osteoporosis and in efforts to reduce incidence and the associated costs of fragility fractures in the population.

Our results concur with the 4 previous studies with hip and/or spine fracture endpoints that DXR-BMD is a strong predictor for fracture. Our results confirm the hip fracture prediction of DXR-BMD in a cohort of cases where hand or wrist X-ray images had been acquired for other purposes, predominantly after suspected wrist fracture. According to these findings, opportunistically applying DXR-BMD processing to hand X-ray images acquired for other purposes, especially at suspected fracture of the wrist or hand, can be an effective method to identify individuals who would benefit from anti-osteoporotic treatment. 



\section{References}

[1] 3rd Hip fractures in the elderly: A world-wide projection. Cooper C, Campion G, Melton LJ., Osteoporos Int. 1992;2:285-9.

[2] Osteoporosis in the European Union: medical management, epidemiology and economic burden. A report prepared in collaboration with the International Osteoporosis Foundation (IOF) and the European Federation of Pharmaceutical Industry Associations (EFPIA). Hernlund E, Svedbom A, Ivergård M, Compston J, Cooper C, Stenmark J, McCloskey EV, Jönsson B, Kanis JA. Arch Osteoporos. 2013;8(1-2):136.

[3] Guidelines for preclinical evaluation and clinical trials in osteoporosis. World Health Organization Geneva. 1998.

[4] Osteoporosis Prevention, Diagnosis, and Therapy. NIH Consens Statement 2000 March 27-29; 17(1): 1-36.

[5] World Health Organization. Assessment of fracture risk and its application to screening for postmenopausal osteoporosis. Technical Report Series, vol. 843. Geneva: WHO; 1994.

[6] Cell. 1996 May 3;85(3):307-10. Rheumatoid arthritis. Feldmann M, Brennan FM, Maini RN.

[7] Clinical course and outcome of early rheumatoid arthritis. Papadopoulos IA, Katsimbri P, Katsaraki A, Temekonidis T, Georgiadis A, Drosos AA. Rheumatol Int 2001, 20:205210.

[8] Rheumatoid arthritis. Klareskog L, Catrina AI, Paget S.Lancet. 2009 Feb 21;373(9664):659-72.

[9] The American Rheumatism Association 1987 revised criteria for the classification of rheumatoid arthritis. Arnett FC, Edworthy SM, Bloch DA, McShane DJ, Fries JF, Cooper NS, Healey LA, Kaplan SR, Liang MH, Luthra HS, Medsger TA, Mitchell DM Jr, Neustadt DH, Pinals RS, Schaller JG, Sharp JT, Wilder RL, Hunder GG. Arthritis Rheum 1988, 31:315-324.

[10] Osteoclast formation and activity in the pathogenesis of osteoporosis in rheumatoid arthritis. Hirayama T, Danks L, Sabokbar A, Athanasou NA. Rheumatology 2002, 41:1232-1239. 
[11] Extra-articular manifestations and complications of rheumatoid arthritis. Young A, Koduri G. Best Pract Res Clin Rheumatol. 2007 Oct;21(5):907-27.

[12] Incidence and Prevalence of Rheumatoid Arthritis, Based on the 1987 American College of Rheumatology Criteria: A Systematic Review. Alamanos, Y. Seminars In Arthritis And Rheumatism Volume: 36 Issue: 3 (2006-12-01) p. 182 - 188.

[13] Cost-effectiveness of infliximab versus conventional combination treatment in methotrexate-refractory early rheumatoid arthritis: 2-year results of the register-enriched randomised controlled SWEFOT trial. Eriksson JK, Karlsson JA, Bratt J, Petersson IF, van Vollenhoven RF, Ernestam S, Geborek P, Neovius M. Ann Rheum Dis. 2014 Apr 15.

[14] Costs of rheumatoid arthritis during the period 1990-2010: a register-based cost-of-illness study in Sweden. Kalkan A, Hallert E, Bernfort L, Husberg M, Carlsson P. Rheumatology (Oxford). 2014 Jan;53(1):153-60.

[15] The cost-effectiveness of TNF-inhibitors for the treatment of rheumatoid arthritis in Swedish clinical practice. Lekander I, Borgström F, Lysholm J, van Vollenhoven RF, Lindblad S, Geborek P, Kobelt G. Eur J Health Econ. 2013 Dec;14(6):863-73.

[16] Cost effectiveness of adalimumab in the treatment of patients with moderate to severe rheumatoid arthritis in Sweden. Bansback NJ, Brennan A, Ghatnekar O. Ann Rheum Dis. 2005 Jul;64(7):995-1002.

[17] European guidance for the diagnosis and management of osteoporosis in postmenopausal women. Kanis JA, McCloskey EV, Johansson H, Cooper C, Rizzoli R, Reginster JY; Scientific Advisory Board of the European Society for Clinical and Economic Aspects of Osteoporosis and Osteoarthritis (ESCEO) and the Committee of Scientific Advisors of the International Osteoporosis Foundation (IOF). Osteoporos Int. 2013 Jan;24(1):23-57.

[18] Technical principles of dual energy x-ray absorptiometry. Blake GM, Fogelman I. Semin Nucl Med. 1997 Jul;27(3):210-28.

[19] Clinical use of bone densitometry: clinical applications. Bates DW, Black DM, Cummings SR. JAMA. 2002 Oct 16;288(15):1898-900.

[20] The 21st century landscape of adult fractures - Cohort study of a complete adult regional population. Rosengren BE, Karlsson M, Petersson I, Englund M. J Bone Miner Res. 2014 Oct 3 .

[21] Assessment of osteoporosis: comparison of radiographic absorptiometry of the phalanges and dual X-ray absorptiometry of the radius and lumbar spine. Takada M, Engelke K, 
Hagiwara S, Grampp S, Jergas M, Glüer CC, Genant HK. Radiology. 1997 Mar;202(3):759-63.

[22] Phalangeal densitometry compared with dual energy X-ray absorptiometry for assessment of bone mineral density in elderly women. Dhainaut A, Rohde G, Hoff M, Syversen U, Haugeberg G. J Womens Health (Larchmt). 2011 Dec;20(12):1789-95.

[23] Comparison of dual-energy X-ray absorptiometry with six quantitative ultrasonometry devices in women with hip fractures. Hadji P, Imani P, Wüster C, Hars O, Albert US, Kyvernitakis I. Climacteric. 2014 Nov 10:1-18.

[24] The radiological diagnosis of osteoporosis: a new approach. Barnett E, Nordin BE. Clin Radiol. 1960 Jul;11:166-74

[25] Digital X-ray radiogrammetry: a new appendicular bone densitometric method with high precision. Jørgensen JT, Andersen PB, Rosholm A, Bjarnason NH. Clin Physiol. 2000 Sep;20(5):330-5.

[26] Estimation of bone mineral density by digital X-ray radiogrammetry: theoretical background and clinical testing. Rosholm A, Hyldstrup L, Backsgaard L, Grunkin M, Thodberg HH. Osteoporos Int. 2001;12(11):961-9.

[27] The Use of Active Shape Models for Locating Structures in Medical Images. Cootes TF, Hill A, Taylor CJ, Haslam J. Image and Vision Computing Vol.12, No.6 July 1994, pp.355-366.

[28] A note on two problems in connexion with graphs. Dijkstra EW. Numerische Mathematik. 1959. 1: 269-271.

[29] A normative reference database study for Pronosco X-posure System. Black DM, Palermo L, Sørensen T, Jørgensen JT, Lewis C, Tylavsky F, Wallace R, Harris E, Cummings SR. J Clin Densitom. 2001 Spring;4(1):5-12.

[30] Hand bone loss as an outcome measure in established rheumatoid arthritis: 2-year observational study comparing cortical and total bone loss. Hoff M, Haugeberg G, Kvien TK. Arthritis Res Ther. 2007;9:R81.

[31] Short-Time In Vitro and In Vivo Precision of Direct Digital X-ray Radiogrammetry. Hoff M, Dhainaut A, Kvien TK, Forslind K, Kälvesten J, Haugeberg G. J Clin Densitom. 2009 Jan-Mar;12(1):17-21. 
[32] Remission and response to early treatment of RA assessed by the Disease Activity Score. BARFOT study group. Better Anti-rheumatic Farmacotherapy. Svensson B, Schaufelberger C, Teleman A, Theander J. Rheumatology 2000, 39:1031-1036.

[33] Low-dose prednisolone in addition to the initial disease-modifying antirheumatic drug in patients with early active rheumatoid arthritis reduces joint destruction and increases the remission rate: a two-year randomized trial. Svensson B, Boonen A, Albertsson K, van der Heijde D, Keller C, Hafström I. Arthritis Rheum 2005, 52:3360-3370.

[34] How to read radiographs according to the Sharp/van der Heijde method. van der Heijde D. J Rheumatol 2000, 27:261-263.

[35] Conventional combination treatment versus biological treatment in methotrexaterefractory early rheumatoid arthritis: 2 year follow up of the randomised, non-blinded, parallel-group Swefot trial. van Vollenhoven RF, Geborek P, Forslind K, Albertsson K, Ernestam S, Petersson IF, Chatzidionysiou K, Bratt J; Swefot study group. Lancet. 2012 May 5;379(9827):1712-20.

[36] Influence of image-capturing parameters on digital X-ray radiogrammetry. Böttcher J, Pfeil A, Rosholm A, Malich A, Petrovitch A, Heinrich B, Lehmann G, Mentzel HJ, Hein G, Linss W, Kaiser WA. J Clin Densitom. 2005 Spring;8(1):87-94.

[37] 2010 rheumatoid arthritis classification criteria: an American College of Rheumatology/European League Against Rheumatism collaborative initiative. Aletaha D, Neogi T, Silman AJ, Funovits J, Felson DT, Bingham CO 3rd, Birnbaum NS, Burmester GR, Bykerk VP, Cohen MD, Combe B, Costenbader KH, Dougados M, Emery P, Ferraccioli G, Hazes JM, Hobbs K, Huizinga TW, Kavanaugh A, Kay J, Kvien TK, Laing T, Mease P, Ménard HA, Moreland LW, Naden RL, Pincus T, Smolen JS, Stanislawska-Biernat E, Symmons D, Tak PP, Upchurch KS, Vencovsky J, Wolfe F, Hawker G. Ann Rheum Dis. 2010 Sep;69(9):1580-8.

[38] Automated measurement of joint space width in small joints of patients with rheumatoid arthritis. Lukas C, Sharp JT, Angwin J, Boers M, Duryea J, Hall JR, Kauffman JA, Landewé R, Langs G, Bernelot Moens HJ, Peloschek P, van der Heijde D. J Rheumatol. 2008 Jul;35(7):1288-93.

[39] Object recognition from local scale-invariant features. Lowe DG. Proceedings of the International Conference on Computer Vision. 1999; Volume 2, pp. 1150-1157. 
[40] Random Sample Consensus: A Paradigm for Model Fitting with Applications to Image Analysis and Automated Cartography. Fischler MA, Bolles RC. Commun. ACM. 1981 June; 24(6):381-395.

[41] Active appearance models. Cootes TF, Edwards GJ, Taylor CJ. Proc. 5th European conference on computer vision. Burkhardt H, Neumann B (eds). Berlin:Springer; 1998. p. 484-498.

[42] Digital X-ray radiogrammetry combined with semiautomated analysis of joint space widths as a new diagnostic approach in rheumatoid arthritis: a cross-sectional and longitudinal study. Böttcher J, Pfeil A, Rosholm A, Petrovitch A, Seidl BE, Malich A, Schäfer ML, Kramer A, Mentzel HJ, Lehmann G, Hein G, Kaiser WA. Arthritis Rheum. 2005 Dec;52(12):3850-9.

[43] Computer-aided joint space analysis (CAJSA) of the proximal-interphalangeal jointnormative age-related and gender specific data. Pfeil A, Böttcher J, Seidl BE, Schäfer ML, Hansch A, Heyne JP, Petrovitch A, Mentzel HJ, Eidner T, Wolf G, Hein G, Kaiser WA. Acad Radiol. 2007 May;14(5):594-602.

[44] ImageNet classification with deep convolutional neural networks. Krizhevsky A, Sutskever I, Hinton GE. Advances in Neural Information Processing Systems. 2012. p. $1097-1105$.

[45] Four-month metacarpal bone mineral density loss predicts radiological joint damage progression after 1 year in patients with early rheumatoid arthritis: exploratory analyses from the IMPROVED study. Wevers-de Boer KV, Heimans L, Visser K, Kälvesten J, Goekoop RJ, van Oosterhout M, Harbers JB, Bijkerk C, Steup-Beekman M, de Buck MP, de Sonnaville PB, Huizinga TW, Allaart CF. Ann Rheum Dis. 2013 Nov 27.

[46] Adalimumab therapy reduces hand bone loss in early rheumatoid arthritis: explorative analyses from the PREMIER study. Hoff M, Kvien TK, Kälvesten J, Elden A, Haugeberg G. Ann Rheum Dis. 2009 Jul;68(7):1171-6.

[47] Evaluation of hand bone loss by digital X-ray radiogrammetry as a complement to clinical and radiographic assessment in early rheumatoid arthritis: results from the SWEFOT trial. Rezaei H, Saevarsdottir S, Geborek P, Petersson IF, van Vollenhoven RF, Forslind K. BMC Musculoskelet Disord. 2013 Mar 5;14:79.

[48] Changes in bone mineral density during long-term treatment with adalimumab in patients with rheumatoid arthritis: a cohort study. Krieckaert CL, Nurmohamed MT, Wolbink G, Lems WF. Rheumatology (Oxford). 2013 Mar;52(3):547-53. 
[49] Loss of metacarpal bone density predicts RA development in recent-onset arthritis. de Rooy DP, Kälvesten J, Huizinga TW, van der Helm-van Mil AH. Rheumatology (Oxford). 2012 Jun;51(6):1037-41.

[50] Bone mineral density by digital X-ray radiogrammetry is strongly decreased and associated with joint destruction in long-standing rheumatoid arthritis: a cross-sectional study. Forsblad-d'Elia H, Carlsten H. BMC Musculoskelet Disord. 2011 Oct 24;12:242.

[51] Accelerated hand bone mineral density loss is associated with progressive joint damage in hands and feet in recent-onset rheumatoid arthritis. Güler-Yüksel M, Klarenbeek NB, Goekoop-Ruiterman YP, de Vries-Bouwstra JK, van der Kooij SM, Gerards AH, Ronday HK, Huizinga TW, Dijkmans BA, Allaart CF, Lems WF. Arthritis Res Ther. 2010;12(3):R96.

[52] Periarticular and generalised bone loss in patients with early rheumatoid arthritis: influence of alendronate and intra-articular glucocorticoid treatment. Post hoc analyses from the CIMESTRA trial. Jensen TW, Hansen MS, Hørslev-Petersen K, Hyldstrup L, Abrahamsen B, Langdahl B, Zerahn B, Pødenphant J, Stengaard-Petersen K, Junker P, Østergaard M, Lottenburger T, Ellingsen T, Andersen LS, Hansen I, Skjødt H, Pedersen JK, Lauridsen UB, Svendsen AJ, Tarp U, Lindegaard H, Jurik AG, Vestergaard A, Hetland ML; Cimestra study group. Ann Rheum Dis. 2014 Jun;73(6):1123-9.

[53] Value of digital X-ray radiogrammetry in the assessment of inflammatory bone loss in rheumatoid arthritis. Pfeil A, Haugeberg G, Hansch A, Renz DM, Lehmann G, Malich A, Wolf G, Böttcher J. Arthritis Care Res (Hoboken). 2011 May;63(5):666-74.

[54] Early changes in bone mineral density measured by digital X-ray radiogrammetry predict up to 20 years radiological outcome in rheumatoid arthritis. Kapetanovic MC, Lindqvist E, Algulin J, Jonsson K, Saxne T, Eberhardt K, Geborek P. Arthritis Res Ther. 2011 Feb $23 ; 13(1): R 31$.

[55] Denosumab prevents metacarpal shaft cortical bone loss in patients with erosive rheumatoid arthritis. Sharp JT, Tsuji W, Ory P, Harper-Barek C, Wang H, Newmark R. Arthritis Care Res (Hoboken). 2010 Apr;62(4):537-44.

[56] Bone mineral density in the hand as a predictor for mortality in patients with rheumatoid arthritis. Book C, Algulin J, Nilsson JA, Saxne T, Jacobsson L. Rheumatology (Oxford). 2009 Sep;48(9):1088-91.

[57] Cortical hand bone loss after 1 year in early rheumatoid arthritis predicts radiographic hand joint damage at 5-year and 10-year follow-up. Hoff M, Haugeberg G, Odegård S, 
Syversen S, Landewé R, van der Heijde D, Kvien TK. Ann Rheum Dis. 2009 Mar;68(3):324-9.

[58] Use of digital $x$ ray radiogrammetry in the assessment of joint damage in rheumatoid arthritis. Jawaid WB, Crosbie D, Shotton J, Reid DM, Stewart A. Ann Rheum Dis. 2006 Apr;65(4):459-64.

[59] Reduced loss of hand bone density with prednisolone in early rheumatoid arthritis: results from a randomized placebo-controlled trial. Haugeberg G, Strand A, Kvien TK, Kirwan JR. Arch Intern Med. 2005 Jun 13;165(11):1293-7.

[60] Hand cortical bone mass and its associations with radiographic joint damage and fractures in 50-70 year old female patients with rheumatoid arthritis: cross sectional OsloTruro-Amsterdam (OSTRA) collaborative study. Haugeberg G, Lodder MC, Lems WF, Uhlig T, Ørstavik RE, Dijkmans BA, Kvien TK, Woolf AD. Ann Rheum Dis. 2004 Oct;63(10):1331-4.

[61] Predicting erosive disease in rheumatoid arthritis. A longitudinal study of changes in bone density using digital X-ray radiogrammetry: a pilot study. Stewart A, Mackenzie LM, Black AJ, Reid DM. Rheumatology (Oxford). 2004 Dec;43(12):1561-4.

[62] Digital X-ray Radiogrammetry Predicts Wrist, Hip, and Vertebral Fracture Risk: A Prospective Analysis from the Study of Osteoporotic Fractures. Bouxsein ML, Palermo L, Yeung C, Black DM. Osteoporos Int. 2002; 13(5):358-365.

[63] Digital X-ray Radiogrammetry Identifies Women at Risk of Osteoporotic Fracture: Results from a Prospective Study. Bach-Mortensen P, Hyldstrup L, Appleyard M, Hindso K, Gebuhr P, Sonne-Holm S. Calcif Tissue Int. 2006 Jul;79(1):1-6.

[64] Metacarpal Radiographic Indices in the assessment of bone strength and fracture risk. Vasireddy S. Dissertation. University of Sheffield. 2010.

[65] Mammography and Osteoporosis Screening-Clinical Risk Factors and Their Association With Digital X-Ray Radiogrammetry Bone Mineral Density. Wilczek ML, Nielsen C, Kälvesten J, Algulin J, Brismar TB. J Clin Densitom. 2014 Oct 4. 



\section{Original publications I-IV}

(Papers reprinted with permission) 


\section{Publications}

The articles associated with this thesis have been removed for copyright reasons. For more details about these see:

http://urn.kb.se/resolve?urn=urn:nbn:se:liu:diva-113680 